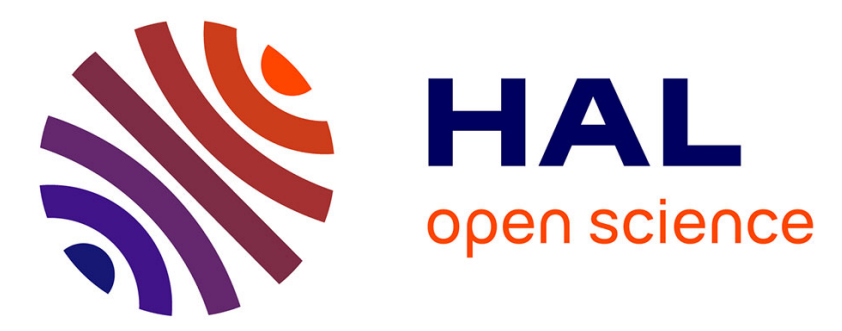

\title{
Discontinuités longitudinales des dynamiques sédimentaires holocènes dans les petites vallées de l'Ouest du Bassin Parisien, l'exemple de la Mue
}

L. Lespez, M. Clet-Pellerin, N. Limondin-Lozouet, J.F. Pastre, Michel

Fontugne

\section{To cite this version:}

L. Lespez, M. Clet-Pellerin, N. Limondin-Lozouet, J.F. Pastre, Michel Fontugne. Discontinuités longitudinales des dynamiques sédimentaires holocènes dans les petites vallées de l'Ouest du Bassin Parisien, l'exemple de la Mue. Quaternaire, 2005, 16 (4), pp.273-298. 10.4000/quaternaire.482 . hal-00292296

\section{HAL Id: hal-00292296 \\ https://hal.science/hal-00292296}

Submitted on 19 Oct 2020

HAL is a multi-disciplinary open access archive for the deposit and dissemination of scientific research documents, whether they are published or not. The documents may come from teaching and research institutions in France or abroad, or from public or private research centers.
L'archive ouverte pluridisciplinaire HAL, est destinée au dépôt et à la diffusion de documents scientifiques de niveau recherche, publiés ou non, émanant des établissements d'enseignement et de recherche français ou étrangers, des laboratoires publics ou privés. 


\title{
DISCONTINUITÉS LONGITUDINALES DES DYNAMIQUES SÉDIMENTAIRES HOLOCÈNES DANS LES PETITES VALLÉES DE L'OUEST DU BASSIN PARISIEN, L'EXEMPLE DE LA MUE (BASSE-NORMANDIE)
}

\author{
L. LESPEZ ${ }^{1}$, M. CLET-PELLERIN² ${ }^{2}$ N. LIMONDIN-LOZOUET ${ }^{3}$, \\ J.-F. PASTRE ${ }^{3}$ et M. FONTUGNE ${ }^{4}$
}

\begin{abstract}
RÉSUMÉ
Les recherches géomorphologiques et paléoenvironnementales entreprises dans la vallée de la Mue contribuent à la connaissance de l'évolution des dynamiques de fonds de vallée dans la Plaine de Caen et plus généralement de la partie sédimentaire de la Basse-Normandie restées à l'écart des études récentes sur l'Holocène. Elles soulignent l'ampleur, l'hétérogénéité et l'originalité des remplissages sédimentaires postglaciaires. L'inventaire systématique du remplissage de cette vallée de $24 \mathrm{~km}$ de long s'est appuyé sur la réalisation de sondages ainsi que sur des carottages dans les secteurs clefs. La sédimentation tardiglaciaire apparaît absente comme dans de nombreuses vallées normandes mais la sédimentation holocène est particulièrement dilatée atteignant 4 à $15 \mathrm{~m}$. Elle obéit à un dispositif longitudinal marqué par la succession de plusieurs tronçons aux caractéristiques morphologiques et sédimentaires différentes. La succession de formations tufacées, tourbeuses, détritiques ou mixtes révèle la complexité du fonctionnement du système fluvial en même temps qu'elle offre un potentiel intéressant pour les analyses multiparamètres. Les analyses sédimentologiques, malacologiques et palynologiques appuyées sur la réalisation de 21 datations radiocarbones permettent de reconstituer la chronostratigraphie des 9 derniers millénaires et d'apprécier le rôle des facteurs paléohydrologiques et anthropiques dans la mutation des milieux sédimentaires. La sédimentation qui s'amorce au début de l'Holocène $\left(9000{ }^{14} \mathrm{C} \mathrm{BP}\right)$ se caractérise par la mise en place de formations tufacées parfois très dilatées (de 7 à $13 \mathrm{~m}$ ) qui sont à l'origine de la construction de véritables seuils dans le fond de vallée. Ce n'est qu'au cours de l'Atlantique et du début du Subboréal (6500-4500 $\left.{ }^{14} \mathrm{C} \mathrm{BP}\right)$ que le remplissage sédimentaire, principalement tourbeux se généralise, en particulier en arrière des seuils à sédimentation carbonatée. Le diachronisme de ces séquences sédimentaires souligne le poids des conditions locales. A partir de l'âge du Bronze $\left(3500{ }^{14} \mathrm{C} \mathrm{BP}\right)$, les formations détritiques résultant de l'érosion des tufs et des sols limoneux des plateaux se développent puis prennent de l'ampleur au cours de l'Âge du Fer et de l'époque gallo-romaine attestant l'emprise croissante des hommes sur les milieux. Cet article souligne l'intérêt d'étendre les recherches dans les trois dimensions des systèmes fluviaux afin de prendre en compte les discontinuités spatio-temporelles des systèmes hydro-sédimentaires holocènes, même dans des vallées de faible ordre.
\end{abstract}

Mots-clés : Holocène, Système fluvial, Tuf, Enregistrements morphosédimentaires, Anthropisation, Normandie, France de l'Ouest.

\section{ABSTRACT}

LONGITUDINAL DISCONTINUITIES OF THE HOLOCENE SEDIMENTATION IN SMALL VALLEYS OF THE WESTERN PARIS BASIN, EXAMPLE OF THE MUE VALLEY

Geomorphologic and palaeoenvironmental researches conducted in the Mue valley allow improving the valley bottom sedimentation knowledge in the Plain of Caen and more generally in the sedimentary area of Lower Normandy, both poorly known areas of the Paris basin. They underline the extent, the heterogeneity and the originality of the Postglacial infilling. The systematic geomorphologic survey in this valley bottom, $24 \mathrm{~km}$ long, is based on boreholes and core drillings in the key areas. The Lateglacial filling is missing like in most of the valleys of Normandy while the Holocene sedimentation is 4 to $15 \mathrm{~m}$ thick. Its longitudinal arrangement is characterized by sections with different morphologic and sedimentary features. The succession of tufaceous, peaty, detritic or mixed deposits illustrates the fluvial system complexity and offers opportunity for multiproxy analyses. To establish the Holocene chronostratigraphy and to determine the role of the palaeohydrologic and anthropogenic control in the sedimentary changes, sedimentologic, malacologic, pollen analyses and radiocarbon dating (21) have been undertaken. The filling begins around $9000{ }^{14} \mathrm{C}$ BP with tufaceous deposits. Locally, they are very thick $(7$ to $13 \mathrm{~m})$ and form barriers in the valley bottom. From the Atlantic and SubBoreal periods (6500-4500 ${ }^{14} \mathrm{C} \mathrm{BP}$ ) peat deposits become widespread, in particular behind the tufa barriers. Nevertheless, the onset of the alluvial aggradation is diachronic along the valley bottom and the alluvial sedimentation has a high variability in relation with the valley morphology and the local geological controls. Since the Bronze Age $\left(3500{ }^{14} \mathrm{C}\right.$ BP) and mainly during the Iron Age and Gallo-Roman period, the spread of detritic

\footnotetext{
${ }^{1}$ Géophen-LETG UMR CNRS 6554 - Université de Caen-Basse-Normandie, laurent.lespez@ geo.unicaen.fr

${ }^{2}$ M2C-UMR CNRS 6143 martine.clet@geos.unicaen.fr

${ }^{3}$ Laboratoire de Géographie Physique UMR CNRS 8591, 1 place A. Briand 92195 Meudon cedex

Nicole.Limondin@cnrs-bellevue.fr, Jean-Francois.Pastre@cnrs-bellevue.fr

${ }^{4}$ LSCE-UMR CEA-CNRS 1572 Michel.Fontugne@1sce.cnrs-gif.fr
} 
alluvial sedimentation derived from the erosion of tufaceous deposits and loamy soils testifies the increase of land use changes within the river basin. However the spatial variability of landscapes and sedimentation is also strongly controlled by local human activities. The research underlines the necessity of longitudinal studies to take into account the spatial and time discontinuities of the Holocene hydro-sedimentary systems even in small order valleys in sedimentary basins.

Key-words: Holocene, Fluvial system, Tufa, Morpho-sedimentary records, Human activities, Normandy, Western France.

\section{I - INTRODUCTION}

L'évolution holocène des fonds de vallées du Bassin parisien est de mieux en mieux connue. Un schéma général des relations entre les dynamiques des systèmes fluviaux, les fluctuations climatiques et l'évolution des sociétés a pu être proposé (Antoine et al., 2003 ; Pastre et al., 1997, 2002a,b, 2003a, b, sous presse). Cependant les données acquises reposent principalement sur des recherches conduites dans les parties centrales et septentrionales du bassin, la partie occidentale et plus particulièrement la Normandie sont globalement restées à l'écart des recherches sur les dynamiques holocènes des fonds de vallées. Dans cette région, seule la vallée de la Seine a fait l'objet d'études récentes et approfondies (Lesueur et al., 2003 ; Sebag, 2002). Pourtant les petites vallées plus sensibles aux transformations de l'environnement et aux conditions de mise en valeur des bassins versants apparaissent comme des milieux privilégiés pour saisir précisément les modalités des changements survenus à l'Holocène (Pastre et al., 1997 ; Orth et al., 2004). Les recherches menées dans la vallée de la Mue, au nord-ouest de la plaine de Caen avaient un double objectif : (1) contribuer à combler ces lacunes en s'appuyant sur un espace où les premières études montraient l'ampleur et la richesse des archives sédimentaires postglaciaires (Coutard et al., 1973 ; Clet-Pellerin et al., 1990 ; CletPellerin 1997), (2) étudier systématiquement l'évolution longitudinale du remplissage holocène, ce qui avait rarement été effectué dans le Bassin parisien (Orth et al., 2004).

\section{II - SECTEUR D'ÉTUDE ET ÉTAT DE LA QUESTION}

La Mue constitue le dernier affluent de la Seulles, cours d'eau côtier bas-normand (fig. 1). Elle draine un bassin versant de petite dimension $\left(97 \mathrm{~km}^{2}\right)$ caractéristique de la Plaine de Caen. Ce cours d'eau d'ordre 2 s'écoule du Sud vers le Nord incisant les calcaires résistants du Bathonien alors que les formations marneuses de Port-en-Bessin qui constituent la base imperméable de cette série n'affleurent qu'à l'amont du bassin versant (fig. 1). Principalement alimentée par l'aquifère du Bathonien, la rivière possède des débits modestes $\left(\right.$ module $\left.=0,353 \mathrm{~m}^{3} \cdot \mathrm{s}^{-1}\right)$ caractérisés par une faible variabilité annuelle et interannuelle avant la mise en place des pompages alimentant l'agglomération caennaise qui ont contribué à accentuer les étiages estivaux (Cador et al., 2001). Depuis le XVIII ${ }^{\mathrm{e}}$ siècle au moins, elle possède un tracé totalement artificiel s'écoulant dans un bief ayant servi à alimenter une vingtaine de moulins (Lespez et al., 2005). Le plateau est recouvert de formations loessiques épaisses de 1,5 à 3 m (Coutard et al., 1973). Comme pour l'ensemble des plateaux calcaires qui entourent Caen, les assolements de la grande culture céréalière (blé, maïs, betterave, protéagineux, cultures fourragères) dominent un paysage d'openfield alors que le fond de vallée, généralement plan, est occupé par des prairies permanentes, des bois ou des friches humides (Cador et al., 2001).

Dans la Plaine de Caen, les analyses paléoenvironnementales demeurent ponctuelles (Ponel et al., 2000 ; Limondin-Lozouet et Preece, 2004 ; Germain-Vallée et Lespez, sous presse). Parfois associées à des fouilles archéologiques (comme à Toufréville, Ponel et al., 2000), elles souffrent de la position des sites qui sont le plus souvent localisés sur les plateaux où seules les formations anthropogènes et les paléosols fossilisés peuvent être exploités du point de vue de l'analyse paléoécologique (Ghesquière et Marcigny, sous presse). Plus développées dans les basses vallées littorales, les recherches, reposent rarement sur un calage chronologique appuyé sur des datations absolues, ce qui rend difficile une interprétation chronostratigraphique précise (Elhaï, 1963 ; Huault, 1972 ; Clet-Pellerin et al., 1977 ; Clet-Pellerin et Verron, 2004). La vallée de la Mue n'a fait l'objet que de deux études paléoenvironnementales préliminaires : l'une, à l'aval, sur le tuf de Reviers et les sédiments tourbeux situés immédiatement en amont (Clet-Pellerin et al., 1990) et l'autre, inédite, à l'amont, à Rots (Clet-Pellerin 1997). Ces recherches attestent l'importance de la sédimentation holocène et suggèrent un dispositif caractérisé par un barrage de tuf à l'aval responsable de la mise en place d'une sédimentation tourbeuse s'étendant vers l'amont sur tout le fond de vallée jusqu'à Rots (Clet-Pellerin et al., 1990). La question du rôle des sociétés dans les dynamiques environnementales au cours des 7 derniers millénaires restait également posée dans un espace au potentiel archéologique très important comme en témoigne le nombre des sites archéologiques recensés du Néolithique à l'époque médiévale et dont plusieurs font ou ont fait l'objet de fouilles programmées ou de prospections approfondies : sites néolithiques de Cairon, Rots et Basly-La Campagne (Clément-Sauleau et al.. 2000, Desloges, 1997 ; Ghesquière et Marcigny, sous presse ; San Juan, 2003, 2004), sites de l'Âge du Fer comme Basly-La Campagne (San Juan, 2003, 2004), église médiévale de Thaon (Delahaye et Niel, 2004), prospections menées par J. Barge et C. Moulin et programme de recherche sur les communes de Thaon et Cairon (San Juan et al., 1999). 


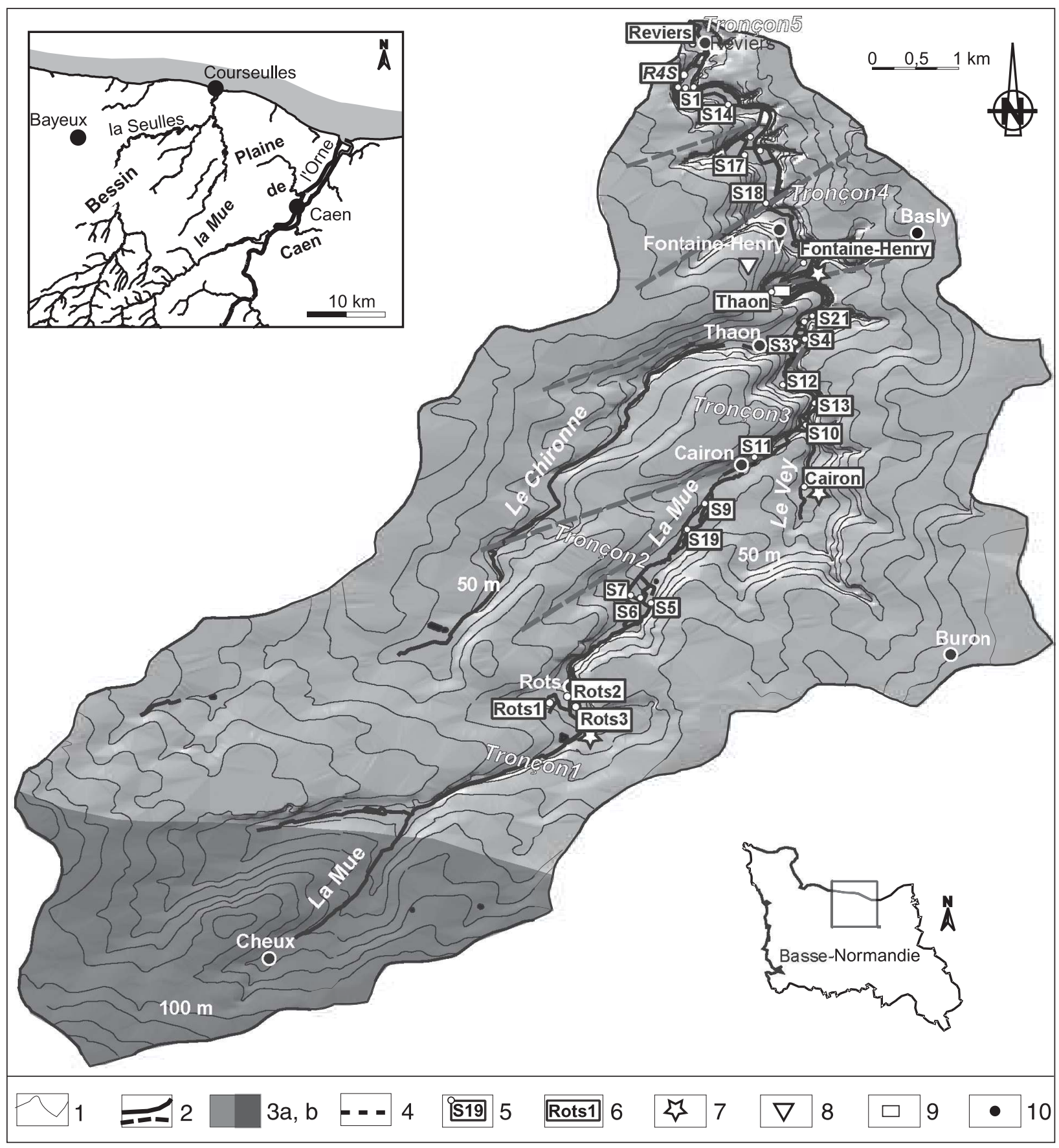

Fig. 1 : Implantation des sondages et carottages dans le bassin versant de la Mue.

1. Courbes de niveau (eq. 5 m) - 2. Ecoulements permanents et temporaires - 3a. Calcaires du Bathonien - 3b. Marnes de Port en Bessin - 4. Principales failles (Maurizot et al., 2000) - 5. Sondages - 6. Carottages - 7. Principaux sites du Néolithique et de l’Âge du Bronze évoqués dans le texte - 8. Principaux sites de l'Âge du Fer et de l'Antiquité évoqués dans le texte - 9. Vieille Eglise de Thaon - 10. Principaux villages.

Fig. 1: Location of borehole and core drilling in the Mue river basin.

1. Contour line $(5 \mathrm{~m})$ - 2. Permanent and intermittent streams - 3a. Bathonian Limestone - 3b. Port-en-Bessin Marls - 4. Main faults (Maurizot et al., 2000) - 5 Boreholes - 6. Core Drillings - 7. Main Neolithic and Bronze Age Sites cited - 8. Main Iron Age and Antique Sites cited-9. Old Church of Thaon - 10. Main villages.

\section{III - MÉTHODES DE LA RECHERCHE}

\section{1 - STRATIGRAPHIE ET SÉDIMENTOLOGIE}

Un inventaire systématique du remplissage alluvial a été effectué grâce à une prospection à la tarière composée de plus de 35 sondages de 3 à $6 \mathrm{~m}$ de profondeur. Ils ont principalement été répartis en fonction de l'évolution des profils en travers et en long afin de fournir une image la plus précise possible de l'organisation longitudinale des archives sédimentaires disponibles pour l'étude de l'Holocène (fig. 1). Même si ce n'était pas l'objectif principal de la recherche, des transects en travers (5) ont également été réalisés afin d'estimer la variabilité latérale du remplissage et sa liaison avec les formations de versant. En fonction de l'intérêt géomorphologique et paléoenvironnemental mais également de considérations géoarchéologiques, trois 
secteurs-clefs ont pu être déterminés pour faire l'objet d'analyses plus approfondies. Dans le secteur de BaslyFontaine-Henry, ont été réalisés des sondages au tractopelle (26), profonds de 1 à 4,5 m et organisés selon 5 transects. Deux carottages profonds de 8 à $9 \mathrm{~m}$ (carottier du Laboratoire de Géographie Physique de Meudon) ont permis d'approfondir la connaissance du remplissage alluvial. Un autre carottage du même type (7 m) complété par un sondage à la tarière $(12 \mathrm{~m})$ a été entrepris sur le tuf de Reviers afin de préciser les données existantes (Clet-Pellerin et al., 1990). Le vallon du Vey, affluent de rive droite de la Mue a également fait l'objet d'un sondage au carottier russe.

Les faciès sédimentaires ont été identifiés par description macroscopique et par des analyses granulométriques réalisées, après destruction de la matière organique, au granulomètre laser (LS 200, Beckman-
Coulter) et des observations des fractions sableuses à la loupe binoculaire. Les analyses sédimentologiques ont porté sur les sédiments transportés et déposés aujourd'hui par le cours d'eau afin de comprendre le fonctionnement actuel du système morphogénique pris comme milieu de référence ( 7 échantillons) et sur les sédiments constituant le remplissage holocène (67 échantillons) afin de déterminer leur mode et leur milieu de dépôt.

Le calage chronostratigraphique des séquences holocènes observées est établi à partir de 21 datations par la méthode du radiocarbone (tab. 1). 12 datations conventionnelles ont été réalisées au Laboratoire des Sciences Climat et de l'Environnement de Gif/Yvette. Le traitement chimique des échantillons a été effectué suivant les protocoles classiques (Délibrias, 1985). Le gaz carbonique obtenu après combustion a été mesuré

\begin{tabular}{|c|c|c|c|c|c|c|c|c|}
\hline Site & $\begin{array}{c}\text { Code } \\
\text { laboratoire }\end{array}$ & Sondage & $\begin{array}{c}\text { Profondeur } \\
\text { (m) }\end{array}$ & Matériel & $\begin{array}{l}\text { Dates }{ }^{14} \mathrm{C} \\
\mathrm{BP}(1 \text { o })\end{array}$ & $\begin{array}{l}\Delta_{\% 0}^{13} \mathrm{C} \\
\%\end{array}$ & \begin{tabular}{|c|} 
Dates \\
calibrées BP \\
$(2$ o $)$
\end{tabular} & Remarques \\
\hline $\begin{array}{l}\text { Thaon-Colonie } \\
\text { de vacances }\end{array}$ & Gif-11716 & S3 & $3,17-3,28$ & $\begin{array}{c}\text { Argile } \\
\text { tourbeuse }\end{array}$ & $4535+/-60$ & $-28,26$ & $\begin{array}{c}\text { 3496-3026 } \\
\text { av. J.-C. }\end{array}$ & \\
\hline $\begin{array}{l}\text { Thaon-Colonie } \\
\text { de vacances }\end{array}$ & Gif-11714 & S3 & $1,90-1,98$ & $\begin{array}{c}\text { Argile } \\
\text { tourbeuse }\end{array}$ & $3300+/-40$ & $-28,05$ & $\begin{array}{l}\text { 1686-1462 } \\
\text { av. J.-C. }\end{array}$ & \\
\hline $\begin{array}{l}\text { Thaon-Vieille } \\
\text { Eglise }\end{array}$ & Erl-6604 & Thaon & $7,20-7,30$ & $\begin{array}{l}\text { Coquille } \\
\text { Cepea }\end{array}$ & $9214+/-68$ & $-12,4$ & $\begin{array}{c}8607-8287 \\
\text { av. J.-C. }\end{array}$ & \\
\hline $\begin{array}{l}\text { Thaon-Vieille } \\
\text { Eglise }\end{array}$ & Erl-6605 & Thaon & $1,79-1,89$ & $\begin{array}{c}\text { Coquille } \\
\text { Cepea }\end{array}$ & $5220+/-69$ & $-12,5$ & $\begin{array}{l}\text { 4243-3806 } \\
\text { av. J.-C. }\end{array}$ & \\
\hline Fontaine-Henry & Gif-11175 & FH11 & $2,47-2,65$ & $\begin{array}{c}\text { Limons } \\
\text { organiques }\end{array}$ & $7740+/-80$ & $-23,1$ & $\begin{array}{c}\text { 6976-6423 } \\
\text { av. J.-C. }\end{array}$ & \\
\hline Fontaine-Henry & Gif-11711 & FH14 & $2,40-2,50$ & $\begin{array}{l}\text { Limons } \\
\text { organiques }\end{array}$ & $3245+/-40$ & $-27,78$ & $\begin{array}{c}1675-1429 \\
\text { av. J.-C. }\end{array}$ & \\
\hline Fontaine-Henry & Gif-11713 & $\mathrm{FH} 25$ & $2,90-3,00$ & $\begin{array}{l}\text { Limons } \\
\text { organiques }\end{array}$ & $5030+/-65$ & $-25,91$ & $\begin{array}{c}\text { 3962-3669 } \\
\text { av. J.-C. }\end{array}$ & \\
\hline Fontaine-Henry & Gif-11864 & FH & $7,71-7,75$ & Tourbe & $4475+/-40$ & $-28,68$ & $\begin{array}{c}\text { 3351-2942 } \\
\text { av. J.-C. }\end{array}$ & \\
\hline Fontaine-Henry & Gif-11863 & $\mathrm{FH}$ & $6,34-6,38$ & Tourbe & $2395+/-40$ & $-28,57$ & $\begin{array}{c}\text { 759-393 av. } \\
\text { J.-C. }\end{array}$ & Non retenue \\
\hline Fontaine-Henry & Gif-11868 & $\mathrm{FH}$ & $5,05-5,10$ & Tourbe & $3150+/-45$ & $-29,65$ & $\begin{array}{c}\text { 1518-1316 } \\
\text { av. J.-C. }\end{array}$ & \\
\hline Fontaine-Henry & Gif-11867 & FH & $3,96-4,01$ & Tourbe & $2420+/-40$ & $-28,6$ & $\begin{array}{c}762-398 \text { av. } \\
\text { J.-C. }\end{array}$ & \\
\hline Fontaine-Henry & Gif-11866 & FH & $2,80-2,90$ & $\begin{array}{l}\text { Limons } \\
\text { tourbeux }\end{array}$ & $3000+/-60$ & $-29,36$ & $\begin{array}{l}\text { 1408-1020 } \\
\text { av. J.-C. }\end{array}$ & Non retenue \\
\hline Fontaine-Henry & Gif-11865 & FH & $1,45-1,52$ & Tourbe & $1500+/-45$ & $-28,3$ & $\begin{array}{c}\text { 436-643 ap. } \\
\text { J.-C. }\end{array}$ & \\
\hline Reviers & Erl-6608 & Reviers & $11,24-11,30$ & $\begin{array}{c}\text { Limons } \\
\text { organiques }\end{array}$ & $7715+/-66$ & $-28,1$ & $\begin{array}{c}\text { 6651-6438 } \\
\text { av. J.-C. }\end{array}$ & \\
\hline Reviers & Erl-6607 & Reviers & $8,45-8,53$ & $\begin{array}{l}\text { Limons } \\
\text { organiques }\end{array}$ & $5989+/-50$ & $-28,9$ & $\begin{array}{c}\text { 4996-4726 } \\
\text { av. J.-C. }\end{array}$ & \\
\hline Reviers & Erl-6606 & Reviers & $6,75-6,80$ & Charbon & $5315+/-45$ & $-29,7$ & $\begin{array}{c}\text { 4317-3999 } \\
\text { av. J.-C. }\end{array}$ & \\
\hline Cairon & Erl-6790 & Cairon & $1,98-2,02$ & $\begin{array}{c}\text { Limons } \\
\text { organiques }\end{array}$ & $8102 \pm 58$ & $-28,3$ & $\begin{array}{c}\text { 7321-6829 } \\
\text { av. J.-C. }\end{array}$ & \\
\hline Cairon & Erl-6789 & Cairon & $1,78-1,81$ & Tourbe & $6695 \pm 49$ & $-29,2$ & $\begin{array}{l}5713-5487 \\
\text { av. J.-C. }\end{array}$ & \\
\hline Cairon & Erl-6788 & Cairon & $1,56-1,59$ & Tourbe & $6242 \pm 49$ & $-29,0$ & $\begin{array}{l}5316-5059 \\
\text { av. J.-C. }\end{array}$ & \\
\hline Cairon & Erl-6787 & Cairon & $0,78-0,82$ & Tourbe & $5108 \pm 47$ & $-29,4$ & $\begin{array}{c}\text { 4033-3791 } \\
\text { av. J.-C. }\end{array}$ & \\
\hline
\end{tabular}

Programme de calibration CALIB rev. 4.3. (Stuiver et Riemer, 1993). 
directement par les techniques habituelles (compteurs proportionnels à gaz, $\mathrm{CO}_{2}$ ). 9 datations AMS ont été réalisées au Physikalishes Institut d'Erlangen. Les âges ${ }^{14} \mathrm{C}$ corrigés du fractionnement biologique (correction de Delta ${ }^{13} \mathrm{C}$ ) sont donc exprimés de manière conventionnelle en années ${ }^{14} \mathrm{C}$ BP (Stuiver et Pollach, 1977). Les intervalles de dates calibrées ont été calculés en utilisant le logiciel Calib rev. 4.3 (Stuiver et Reimer, 1993) au niveau de confiance 95,4 \% (2 sigma).

\section{2 - ANALYSES PALÉO-BIOLOGIQUES}

Les sédiments tourbeux des carottages de FontaineHenry, de Reviers et de Cairon ont fait l'objet d'analyses polliniques systématiques. L'intervalle de prélèvement est compris entre 3 et $10 \mathrm{~cm}$. Les échantillons ont été préparés par tamisage entre 125 et $10 \mu \mathrm{m}$ et attaque à l'acide fluorhydrique. 56 échantillons ont été étudiés dans la séquence tourbeuse de Fontaine-Henry, 42 dans celle de Rots (Rots 3), 22 dans celles de Cairon et 6 sur les horizons organiques interrompant la sédimentation carbonatée du tuf de Reviers.

La séquence tufacée de l'Eglise de Thaon a fait l'objet d'analyses malacologiques. L'échantillonnage a été effectué sur la totalité du carottage qui représente 7,60 mètres d'épaisseur. Les prélèvements malacologiques s'échelonnent en continu sur l'ensemble des niveaux tufacés, leur épaisseur peut varier de 4 à $15 \mathrm{~cm}$ en fonction de la lithologie, la valeur moyenne étant de $10 \mathrm{~cm}$. Les prélèvements ont été traités selon le protocole décrit par Puisségur (1976).

\section{IV - LA COMPLEXITÉ DES SYSTÈMES MORPHOSÉDIMENTAIRES HOLOCÈNES}

\section{1 - MORPHOLOGIE DU FOND DE VALLÉE ET} AMPLEUR DE LA SÉDIMENTATION HOLOCÈNE

Longue de 24 kilomètres, la vallée de la Mue possède un profil en long complexe qui correspond à 5 tronçons qui se succèdent d'amont en aval (fig. 2). Les tronçons pentus $(3,5$ à $7,4 \%$ o souvent étroits $(50-75 \mathrm{~m})$ alternent avec les tronçons larges (120 à $500 \mathrm{~m}$ ) et en pente faible (1 à $2 \%$ ). Ce dispositif résulte de la tectonique de domaine intraplaque qui a affecté la rive sud de la Manche au Plio-Quaternaire. Elle est responsable d'un rajeunissement du relief qui s'est manifesté par une tectonique de bloc et en particulier par le soulèvement du plateau côtier de la Seulles (Font, 2002). Le soulèvement d'un bloc entre Lasson et Thaon est sans doute responsable de l'accentuation de la pente sur le troisième tronçon de la rivière. A cela s'ajoutent de nombreuses failles parallèles de direction N50 (Maurizot et al., 2000) qui guident les nombreuses sinuosités dans le bassin versant de la Mue (Font, 2002) et en particulier les méandres qui se succèdent à partir de Cairon (fig. 1).

Une quinzaine de sondages et de carottages ont permis d'atteindre le substrat ou la grave de fond attribuable à la dernière période froide. Ils permettent de se faire une idée assez précise de l'ampleur de la sédimentation post-glaciaire qui s'accentue progressivement vers l'aval passant de 4 mètres au début du deuxième

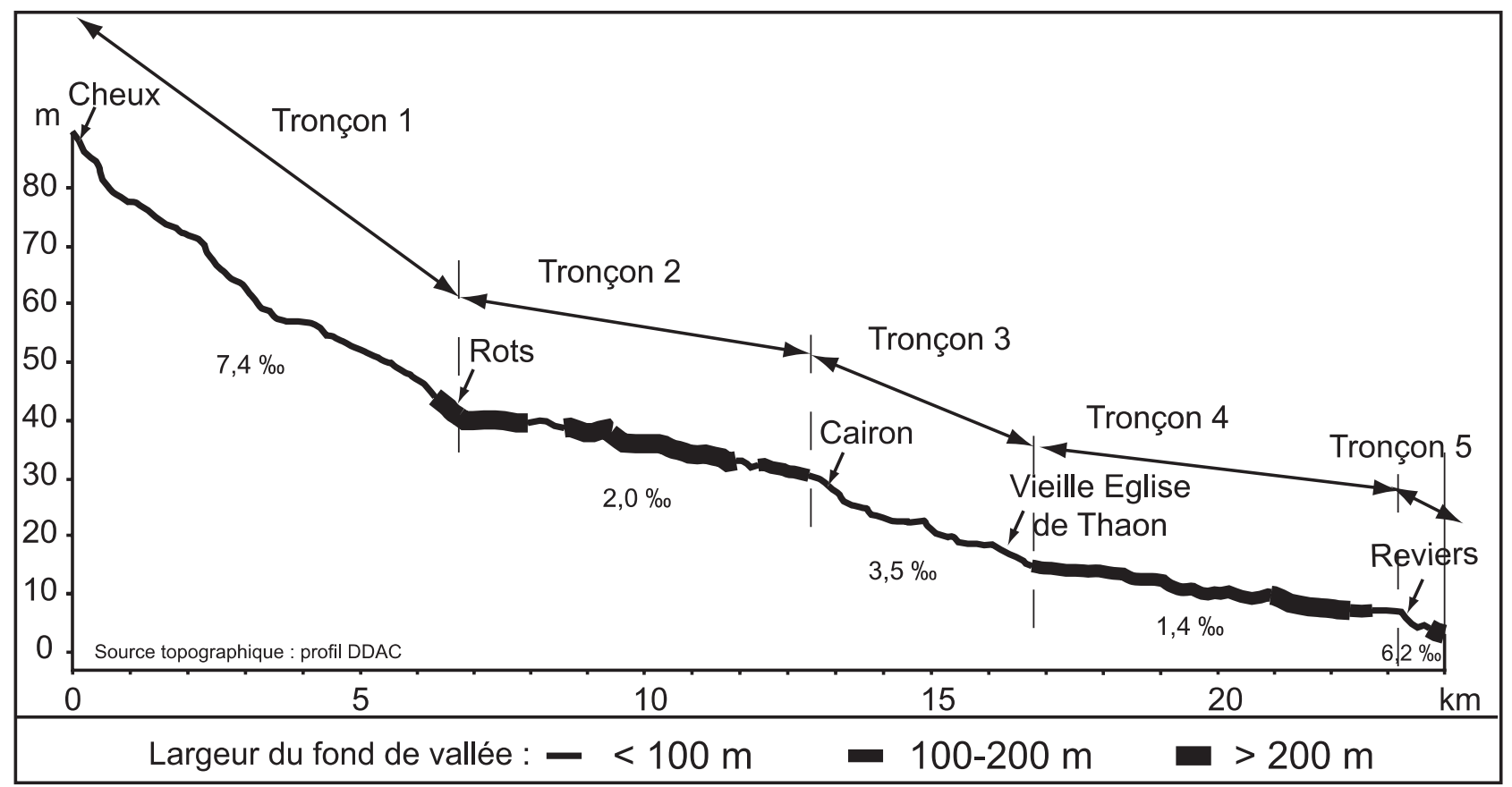

Fig. 2 : Profil en long et largeur du fond de vallée

L'irrégularité de détail du profil en long du cours d'eau actuel s'explique par son artificialisation et la création des chutes associées à d'anciens moulins.

Fig. 2: Longitudinal profile and valley bottom width

The local complexity of the longitudinal profile is explained by the artificialization of the stream and particularly by the mill system and the associated waterfalls. 


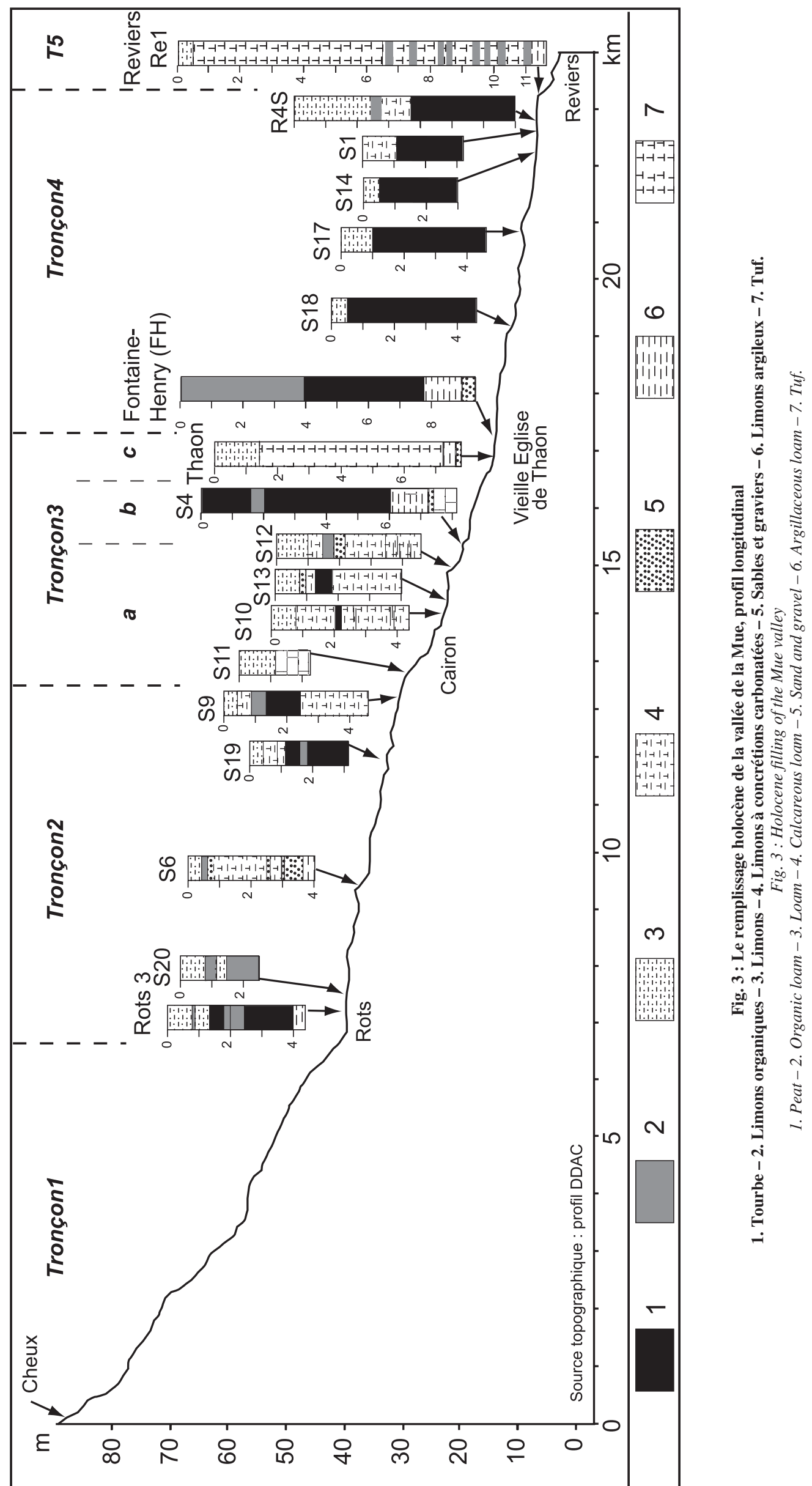


tronçon à plus de 12 mètres sur le cinquième. Seuls, le premier et le début du troisième tronçon possèdent une sédimentation faible (fig. 3). Cette ampleur remarquable de la sédimentation, pour une vallée de petite dimension qui ne débouche pas directement sur le littoral, montre l'importance des processus de comblement tout au long de l'Holocène.

\section{2 - LES FACIÈS SÉDIMENTAIRES}

La nature du remblaiement holocène apparaît très variée. Les observations de terrain couplées aux analyses de laboratoires permettent de distinguer 7 grands types de faciès sédimentaires. La classification proposée repose en partie sur l'utilisation des indices du grain moyen et de tri (So) de Folk et Ward (1957) calculés sur la fraction du sédiment inférieure à $2 \mathrm{~mm}$ (fig. 4) et sur les observations macroscopiques pour les sédiments les plus grossiers (Tab. 2).

\begin{tabular}{|c|c|c|}
\hline Types & Caractéristiques & Milieux de dépôt \\
\hline Groupe 1 & $\begin{array}{c}\text { Sables ou graviers } \\
\text { tufacés }\end{array}$ & $\begin{array}{c}\text { Encroûtements mobiles } \\
\text { alluviaux } \\
\text { ou associés aux zones } \\
\text { sourceuses }\end{array}$ \\
\hline Groupe 2 & Sables fluviatiles & Chenal \\
\hline Groupe 3 & Limons alluviaux & Plaine d'inondation \\
\hline Groupe 4 & Limons fins & Milieu palustre, eau libre \\
\hline Groupe 5 & Limons fins organiques & Milieu palustre \\
\hline Groupe 6 & $\begin{array}{c}\text { Limons hétérométriques } \\
\text { carbonatés }\end{array}$ & Bord de chenal, berge \\
\hline Groupe 7 & Tourbe & Bas-marais \\
\hline \multicolumn{3}{|c|}{ Tab. 2 : Faciès sédimentaire. } \\
Tab. 2: Sedimentary facies.
\end{tabular}

\section{Les sables ou graviers tufacés (Groupe 1)}

Les sables ou les graviers carbonatés sont très abondants dans la sédimentation holocène. Il s'agit de sables ou de graviers oncolitiques constitués de granules calcaires arrondis de 0,5 à $2-3 \mathrm{~cm}$ de diamètre ou de concrétions de forme allongée de type tube ou de fragments de ces deux types de concrétions. Ils se forment autour de grains de sables (oncolithes) ou de brindilles et de fragments de branchages dans les zones d'exsurgences issues des calcaires du Bathonien ou le long des berges du cours d'eau. Ils peuvent être remaniés lors des crues et constituent des édifices tufacés de type « encroûtement mobile» d'origine algaire et bactérienne (Adolphe et Rofes, 1973 ; Freytet, 1990).

\section{Les sables fluviatiles (Groupe 2)}

Les sables fluviatiles sont dans l'ensemble très mal triés car ils proviennent de bancs de sables hétérométriques plus ou moins vaseux déposés par excès de charge à la fin des crues de la Mue. Il existe, cependant, des sables grossiers et des graviers un peu mieux triés ( $\mathrm{So}=2,5$ pour le sable échantillonné) qui résultent de dépôts de courant dans les tronçons de bief possédant des écoulements rapides. Ils correspondent à des grains de calcaire du Bathonien, de quartz, de feldspaths et de fragments de concrétions carbonatées. Ces faciès ne constituent jamais des faciès dominants dans les sondages mais on les rencontre ponctuellement.

\section{Les limons alluviaux (Groupe 3)}

Il s'agit de limons qui possèdent un mauvais indice de tri $(2,5<$ So $<4)$ et un grain moyen qui varie de 20 à $40 \mu \mathrm{m}$ environ. Ils correspondent à des limons (>70\%) à sables fins $(>15 \%)$ et possèdent un mode compris entre 40 et $50 \mu \mathrm{m}$. Ils se rapprochent donc des limons éoliens weichséliens carbonatés de la Plaine de Caen (Lautridou, 1985) mais leur mauvais indice de tri indique d'importants remaniements pendant ou après leur transport vers le fond de vallée. Il s'agit principalement de limons de débordement déposés dans les prairies humides de fond de vallée.

\section{Les limons fins (Groupe 4)}

Ils se caractérisent par un tri modéré dans l'absolu (So 2) mais qui apparaît très bon en regard des autres sédiments analysés. Il s'agit de limons qui possèdent un mode $(45 \mu \mathrm{m})$ proche des limons loessiques, une teneur en argile et en limons fins non-négligeable. Leur bon tri relatif s' explique principalement par la faiblesse de la fraction sableuse moyenne. Ils témoignent sans doute d'une mise en place dans le fond de vallée par des processus de décantation dans des milieux palustres et d'un faible remaniement post-dépositionnel.

\section{Les limons fins organiques (Groupe 5)}

Il s'agit de limons riches en matière organique, parfois tourbeux, qui possèdent une distribution souvent pluri-modale responsable de leur très mauvais tri (So $>4)$. Les courbes granulométriques montrent un mode principal correspondant aux limons loessiques et un épaulement vers les fines (limons fins, argile) expliquant la faiblesse du grain moyen (le pourcentage d'argile peut être compris entre 10 et $15 \%$ ). Il s'agit d'un mélange de limons et d'argile déposés dans des milieux palustres.

\section{Les limons hétérométriques carbonatés (Groupe 6)}

Il s'agit de sédiments très mal triés (So>6) qui comportent fréquemment une fraction grossière $(>2 \mathrm{~mm})$ constituée de graviers. La fraction inférieure à $2 \mathrm{~mm}$ (fig. 4) possède une distribution pluri-modale qui indique clairement un mélange à peu près équilibré entre des limons, des argiles (15 à $30 \%$ ) et des sables (15-30\%). La fraction grossière (sables et graviers) est constituée de fragments d'oncolites ou de tubes, de coquilles de mollusques et de rares concrétions intactes. Ces formations témoignent donc du remaniement de formations tufacées et d'un dépôt par sédimentation forcée en fin de crue sur le bord du chenal ou sur ses berges.

\section{La tourbe (Groupe 7)}

La sédimentation organique fibreuse dépourvue d'apports détritiques longitudinaux est rare dans les 


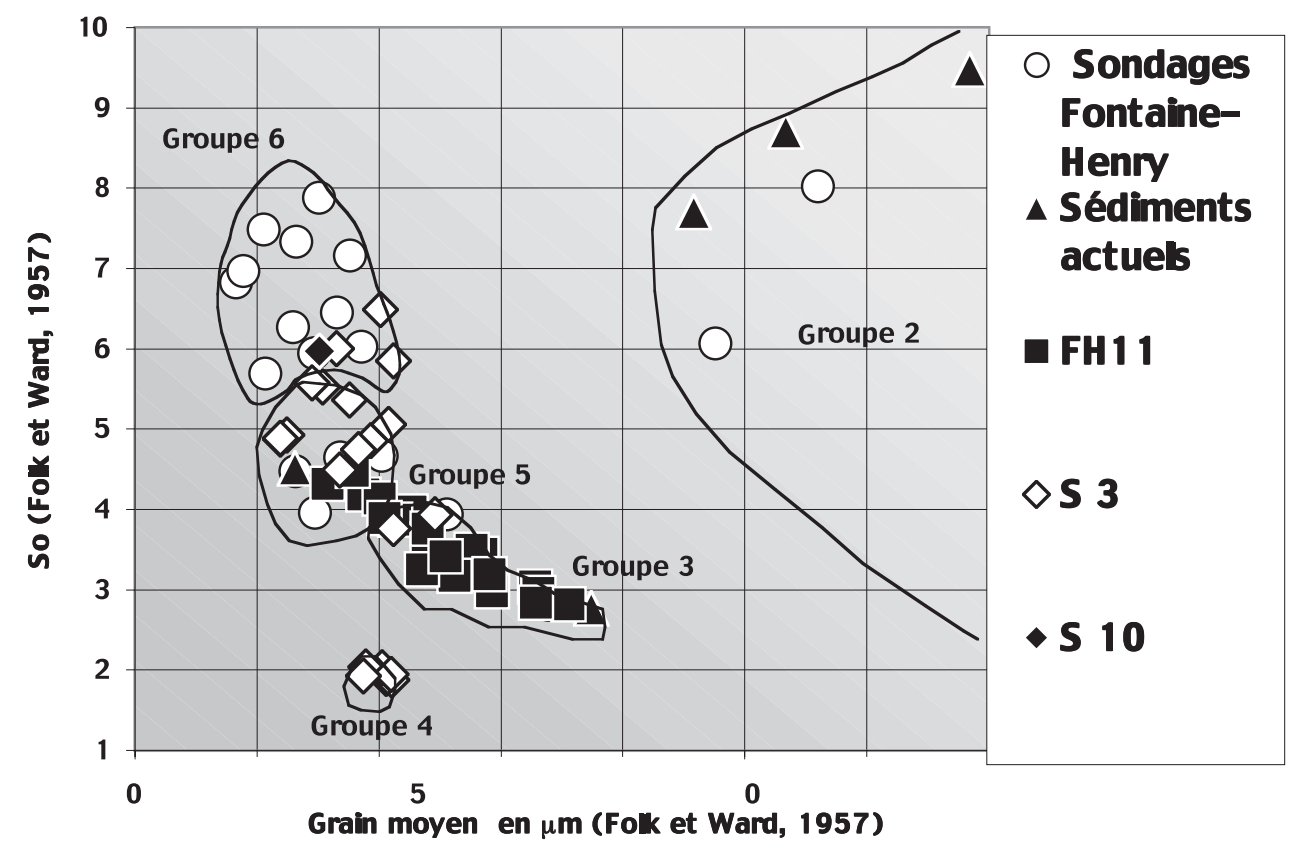

Fig. 4 : Typologie des échantillons en fonction de leur taille moyenne et de leur tri granulométrique (fraction $<2 \mathrm{~mm}$ ). Fig. 4: Granulometric samples types in relation with Mean Grain Size and Sorting (grain $<2 m m$ ).

environnements fluviatiles de bas marais. Dans la vallée de la Mue, la sédimentation tourbeuse comporte fréquemment une fraction argilo-limoneuse et ne se développe véritablement qu'à la base de séquences organiques limoneuses (Groupe 5).

\section{3 - UN DISPOSITIF MORPHOSÉDIMENTAIRE TRONÇONNÉ LONGITUDINALEMENT}

L'organisation complexe de la vallée de la Mue impose un examen longitudinal du remplissage sédimentaire holocène qui s'appuie sur les tronçons définis (fig. 3).

Tronçon 1 et vallées affluentes : faiblesse de la sédimentation holocène

Les sondages effectués dans le tronçon 1 et dans les vallées affluentes soulignent la faiblesse de la sédimentation holocène. Comme la Mue amont, le Chironne possède une sédimentation holocène inférieure à $2 \mathrm{~m}$ constituée de limons colluviaux faiblement remaniés longitudinalement.

Le Vey, affluent de rive droite de la Mue possède un remplissage holocène plus varié mais guère plus épais (2 à 2,5 m). A l'amont domine une sédimentation limoneuse alors que vers l'aval un colmatage organique se développe. Un carottage (Cairon) effectué dans le fond de vallée permet de distinguer la succession de 4 unités (fig. 6). La base est constituée de limons sableux grisvert, moins sableux et plus gris vers le sommet (U1Cairon, Gpe 2). U2-Cairon correspond à l'alternance de limons organiques laminés ou de tourbe et de limons tourbeux à granules entre la fin du Boréal $(8102+/-58$ ${ }^{14} \mathrm{C} \mathrm{BP}$ ) et le début de l'Atlantique (après $6695+/-49$ $\left.{ }^{14} \mathrm{C} \mathrm{BP}\right)$. Cette sédimentation est recouverte par une tourbe noire à la fin de l'Atlantique et au début du Subboréal (U3-Cairon, entre $6242+/-49{ }^{14} \mathrm{C}$ BP et $5108+/-47{ }^{14} \mathrm{C} \mathrm{BP}$ ) puis par des sédiments limoneux plus ou moins organiques à fragments de concrétions carbonatées (U4-Cairon-2003).

Tronçon 2 : alternance de sédiments carbonatés et sédiments organiques

À Rots, la sédimentation holocène dilatée dans l'axe de la vallée (4 mètres, Rots 3 ) apparaît réduite sur ses marges, $3 \mathrm{~m}$ en rive droite (Rots 2 ) et 1,5 mètres en rive gauche (Rots 1) (fig. 5a et 6). La stratigraphie est caractérisée par la succession de six unités sédimentaires. En l'absence de datations par la méthode du radiocarbone, l'étude pollinique permet d'estimer l'âge de ces séquences (cf. infra). U1R est constituée de sables et des graviers calcaires qui forment localement la grave de fond (Rots 3 ). U2R correspond à des limons gris, argileux au centre de la vallée (Gpe 4), ils sont plus sableux sur les marges (U3R). Se développe ensuite une séquence tourbeuse de plus en plus limoneuse vers le sommet attribuable à l'Atlantique (U4R, Gpe 7, Rots 1 et Rots 3). U5R constitue une passée sablo-limoneuse à nombreux fragments de concrétions carbonatées (Gpe 6). U6R forme une nouvelle séquence tourbeuse souvent très limoneuse attribuable au Subatlantique. U7R date des derniers siècles et est constituée de limons gris plus ou moins sableux (Gpe 3). Ce remplissage est proche de celui observé sur S19.

$\mathrm{Au}$ milieu de ce tronçon, la sédimentation est dominée par les faciès carbonatés. A Vauculay, trois sondages S5, S6, S7 montrent une sédimentation qui possède une ampleur variable (fig. 5b). Elle dépasse 4 mètres dans l'axe de la vallée (S6), mais n'est plus que de 2,5 mètres en rive gauche $(\mathrm{S} 7)$ et de 0,5 mètre 


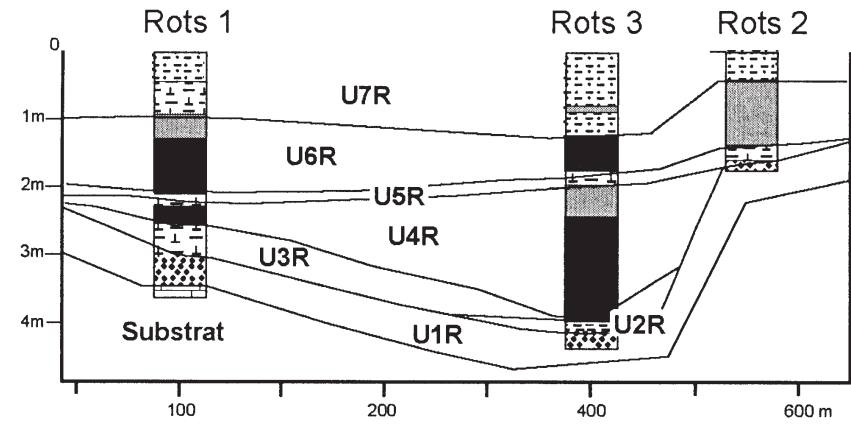

Fig. 5a : Coupes morphostratigraphiques des séquences sédimentaires de la vallée de la Mue à Rots (cf. fig. 3).

Fig. 5a: Morphostratigraphical cross section of the Mue at Rots (cf. fig. 3).

sur la rive droite (S5). La stratigraphie est caractérisée par la succession de 5 unités sédimentaires. À la base (U1V), un horizon de sables et de graviers calcaires (S7) repose sur le substrat calcaire. U2V correspond à des sédiments limoneux gris plus ou moins organiques et sableux (Gpe 3). U3V forme une séquence alluviale constituée de sables et de graviers calcaires émoussés (Gpe 1). U4V est constituée de limons très riches en concrétions carbonatées (Gpe 6). L'ensemble du fond de vallée est ensuite colmaté par des apports limoneux (U5V, Gpe 3).

$\mathrm{Au}$ Bout de Rosel (S9), une séquence tourbeuse repose sur une sédimentation argilo-limoneuse à nombreuses concrétions ou fragments de concrétions calcaires.

Tronçon 3 : sédimentation complexe où alternent sédimentation carbonatée et sédimentation organique

Ce tronçon débute par une section (S11, Cairon) où, selon les données disponibles, la sédimentation holocène semble très peu développée. Vers l'aval, elle se dilate et devient plus complexe nécessitant l'identification de trois sections $(a, b, c)$.

De la confluence avec le Vey, affluent de rive droite, jusqu'à la confluence avec le Chironne, affluent de rive gauche, la sédimentation présente la succession de 6 unités sédimentaires. A la base, on retrouve ponctuellement (S3) un horizon sablo-argileux (U1CT). U2CT correspond à un horizon argileux-limoneux gris qui comporte de rares concrétions carbonatées (S3, S4, Gpe 4). U3CT correspond à des sédiments argilo-limoneux blanchâtres qui comportent de nombreuses concrétions carbonatées de type oncolitique (Gpe 6) et des passées tourbeuses (Gpe 7). Une datation radiocarbone obtenue au milieu de cet horizon sur le sondage S3 indique un âge de $4535+/-60{ }^{14} \mathrm{C} \mathrm{BP}$ et le date du Subboréal. U4CT correspond à une passée organique datée au sommet de S3 de la fin du Subboréal (3300 +/- 40 $\left.{ }^{14} \mathrm{C} \mathrm{BP}\right)$. U5CT correspond à un horizon détritique limoneux qui comporte de nombreuses concrétions et fragments de concrétions carbonatées (Gpe 6). La dernière unité sédimentaire (U6CT) correspond à des limons comportant beaucoup moins de fragments de concrétions et qui sont localement tourbeux (Gpe 3).

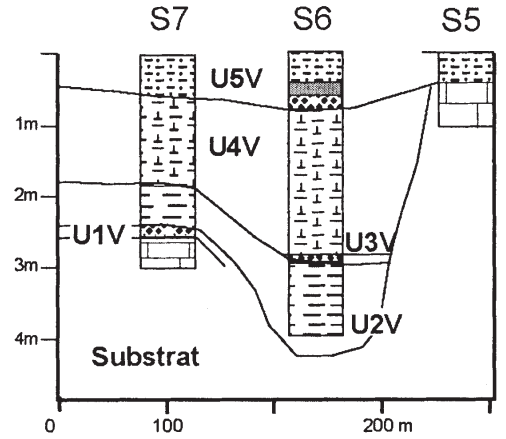

Fig. 5b : Coupes morphostratigraphiques des séquences sédimentaires de la vallée de la Mue à Vauculay (cf. fig. 3).

Fig. 5b: Morphostratigraphical cross section of the Mue at Vauculay (cf. fig. 3).

Vers le centre de la vallée au niveau de la confluence avec le Chironne et vers l'aval, la sédimentation devient beaucoup plus tourbeuse et montre la succession de 5 unités sédimentaires (S4). Un limon gris argileux (U2TCV) repose sur le substrat calcaire (Gpe 3). Il est recouvert par une sédimentation tourbeuse épaisse de 3,5 à 5 mètres (U3TCV) datant du Subboréal et du Subatlantique d'après une datation obtenue au milieu de $\mathrm{S} 4\left(3805+/-40{ }^{14} \mathrm{C} \mathrm{BP}\right)$. U4TCV correspond à des limons organiques (Gpe 4) et est interrompue par une passée limoneuse à fragments de concrétions carbonatées (U5CVT, Gpe 6) qui est l'équivalent latéral sur S4 de U5CT de S3. La sédimentation est ensuite le plus souvent limoneuse (Gpe 3) sauf dans quelques rares espaces où une sédimentation limono-tourbeuse persiste jusqu'à aujourd'hui (U6TCV).

Ce tronçon se termine à la Vieille Eglise de Thaon où la sédimentation holocène est principalement carbonatée (Thaon). On distingue 5 unités sédimentaires (fig. 7). A la base, des limons sableux gris-vert possèdent une forte charge caillouteuse calcaire (U1-Thaon, Gpe 3). U2-Thaon correspond à des limons argileux gris (Gpe 3). Des coquilles de Cepea (mollusques de prairie) prélevées au sommet de cette unité ont pu être datées et donnent un âge Préboréal pour cette unité $\left(9214+/-68{ }^{14} \mathrm{C} \mathrm{BP}\right)$. C'est sur cet horizon que s'est construit un vaste édifice tufacé venu former un véritable barrage dans le fond de la vallée. La sédimentation carbonatée correspond d'abord à des encroûtements mobiles de type tubes puis à des fragments de concrétions de petite dimension dans une matrice limono-sableuse assez développée (U3Thaon, Gpe 1). Cette sédimentation est interrompue par de rares passées plus grises et plus fines (Gpe 6). A partir de 5,3 mètres se développe une formation plus grossière où les oncolithes apparaissent souvent dominants (U4-Thaon). Une datation sur coquilles de Cepea a pu être obtenue au sommet de cette séquence. Elle donne un âge de $5220+/-69{ }^{14} \mathrm{C}$ BP et montre que l'édifice tufacé de la Vieille Eglise de Thaon s'est principalement construit au cours du Boréal et de l'Atlantique. Les limons qui recouvrent cette formation sont gris et plus ou moins carbonatés et humifères (U5-Thaon, Gpe 3 et 6). 


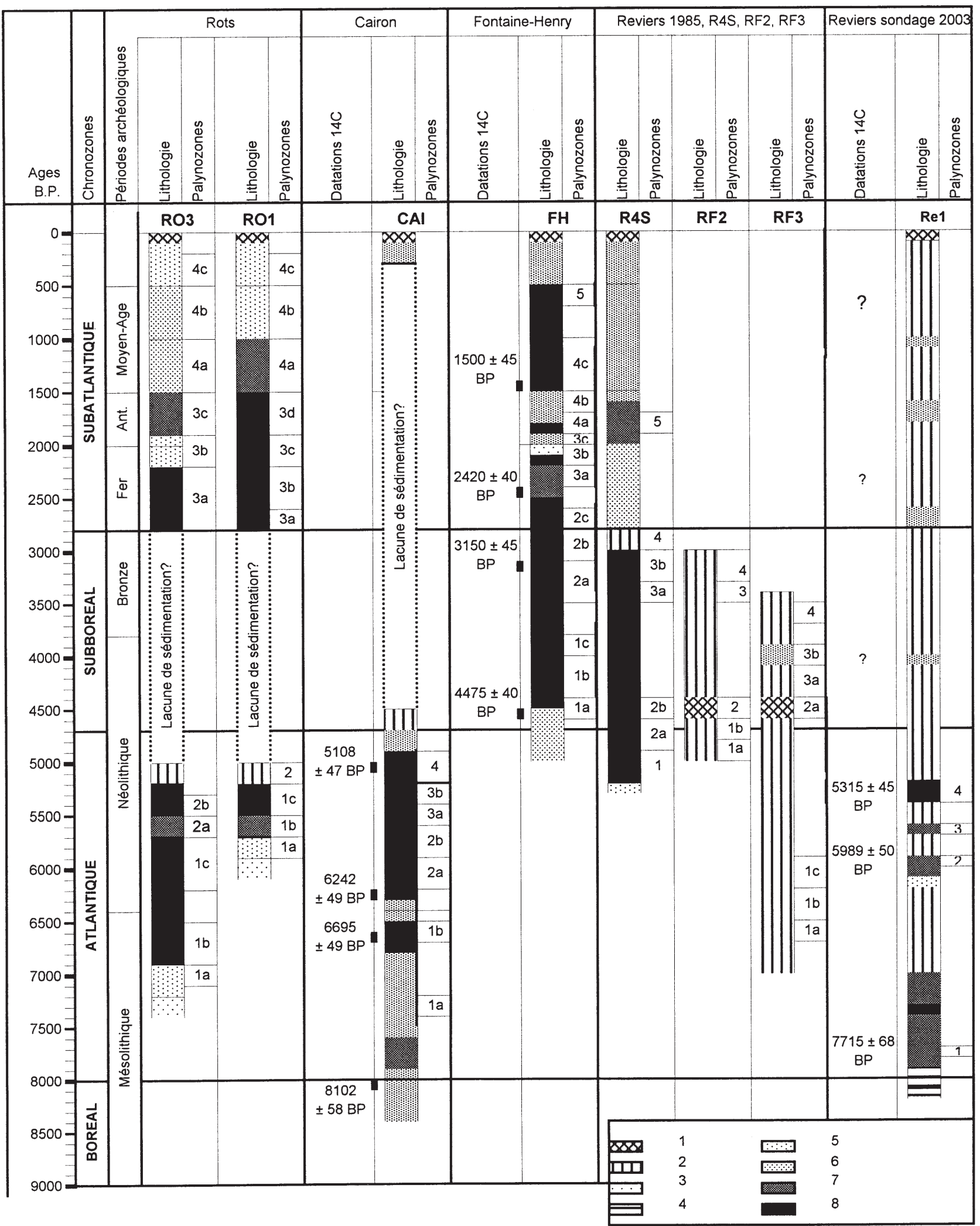

Fig. 6 : Chronostratigraphie et palynozone des principaux carottages de la vallée dans la vallée de la Mue.

1. Sol - 2. Tuf - 3. Sable - 4. Argile - 5. Limon sableux - 6. Limon - 7. Limon organique - 8. Tourbe. Les limites des chronozones sont celles admises pour le Bassin parisien (Pastre et al., 2003b).

Fig. 6: Chronostratigraphy and Pollen zone of the main core drillings in the Mue valley.

1. Soil-2. Tufa-3. Sand-4. Clay - 5. Loamy sand-6. Loam-7. Organic loam-8. Peat. The chronozone limits are those admitted for the Paris Basin (Pastre et al., 2003b). 


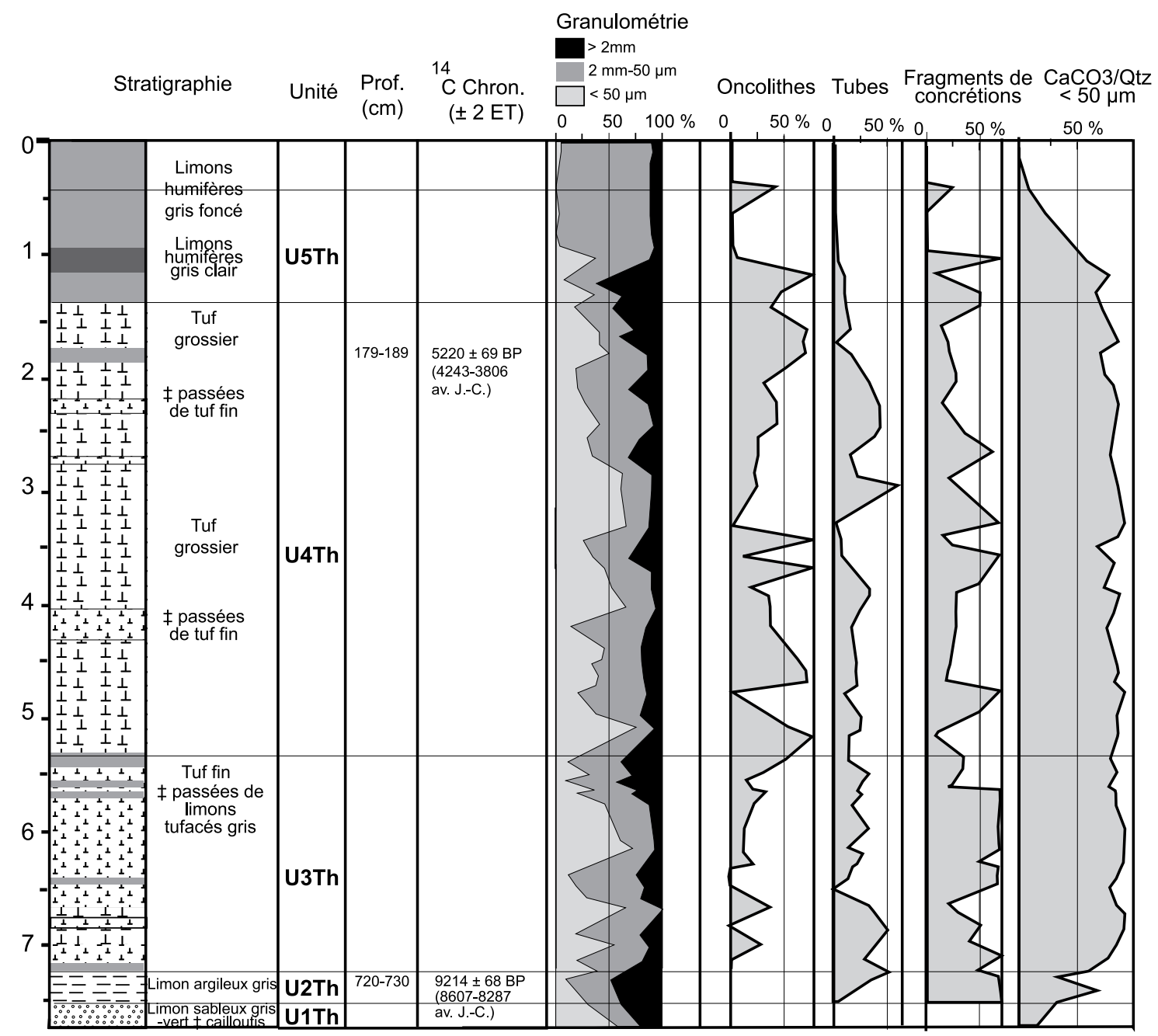

Fig. 7 : Chronostratigraphie et analyses sédimentologique du carottage de Thaon.

Fig. 7: Chronostratigraphy and sedimentological analyses of the Thaon core drilling.

\section{Tronçon 4 : une sédimentation organique}

La sédimentation tourbeuse se développe sur plus de $6 \mathrm{~km}$ de long (Fontaine-Henry, S18, S17, S14, S1, R4S) et sur une épaisseur qui peut dépasser 7 mètres. Le carottage de Fontaine-Henry (fig. 8a, b) montre à la base une grave grossière beige $(\mathrm{U} 1 \mathrm{FH})$ sur laquelle se sont déposés des limons gris à gris-vert sableux comportant quelques gravillons de calcaires (U2FH, Gpe 3). U3FH correspond à une tourbe fibreuse (Gpe 7) qui se développe à partir de $4475+/-40{ }^{14} \mathrm{C} \mathrm{BP}$ et jusqu'à $2420+/ 40{ }^{14} \mathrm{C} \mathrm{BP}$, c'est-à-dire pendant la deuxième partie du Subboréal. U4FH correspond à des limons tourbeux comportant de belles passées limoneuses grises (Gpe 4, 3) qui se développent jusque vers $1500+/-45{ }^{14} \mathrm{C} \mathrm{BP}$ environ. U5FH correspond à une tourbe plus fibreuse qui marque l'arrêt des apports limoneux réguliers (Gpe 7). Vers l'aval le sondage R4S (fig. 6) montre une séquence tourbeuse (Gpe 7) attribuable au Subboréal d'après l'étude du contenu pollinique (Clet-Pellerin et al., 1990), recouverte par un horizon tufacé (Gpe 6) et une séquence limoneuse épaisse de plus de 2,5 mètres (Gpe 3). L'ampleur du colmatage limoneux final est plus ou moins importante selon les sondages.
Entre les carottages de Thaon (U3-4Thaon) et celui de Fontaine-Henry (U3-4FH), on observe donc le passage d'une sédimentation carbonatée, mise en place pendant la première partie de l'Holocène, à une séquence tourbeuse déposée pendant la seconde partie. La transition entre ces deux sondages séparés par environ 600 mètres peut être décrite par la succession de 6 sondages à peu près équidistants (fig. 8a, 8b). On passe progressivement des tufs non-consolidés de l'amont à un sédiment organo-carbonaté résultant du mélange de sédiments tourbeux qui forment parfois de belles passées homogènes (Gpe 7) et de sédiments constitués de limons argileux carbonatés comprenant fréquemment des fragments d'oncolithes, de tubes, des coquilles et plus rarement des éléments intacts (Gpe 6). Cette succession montre l'érosion progressive de l'édifice tufacé et le remaniement de ses sédiments alors que s'affirme le pôle organique dans la deuxième partie de l'Holocène.

L'examen de deux transects (fig. 8a et 9a, b) permet d'examiner le lien entre la sédimentation du fond de vallée et les versants qui la dominent. Sur la rive concave (fig. 9a), les sédiments holocènes reposent directement au contact de la roche en place. Au cours 


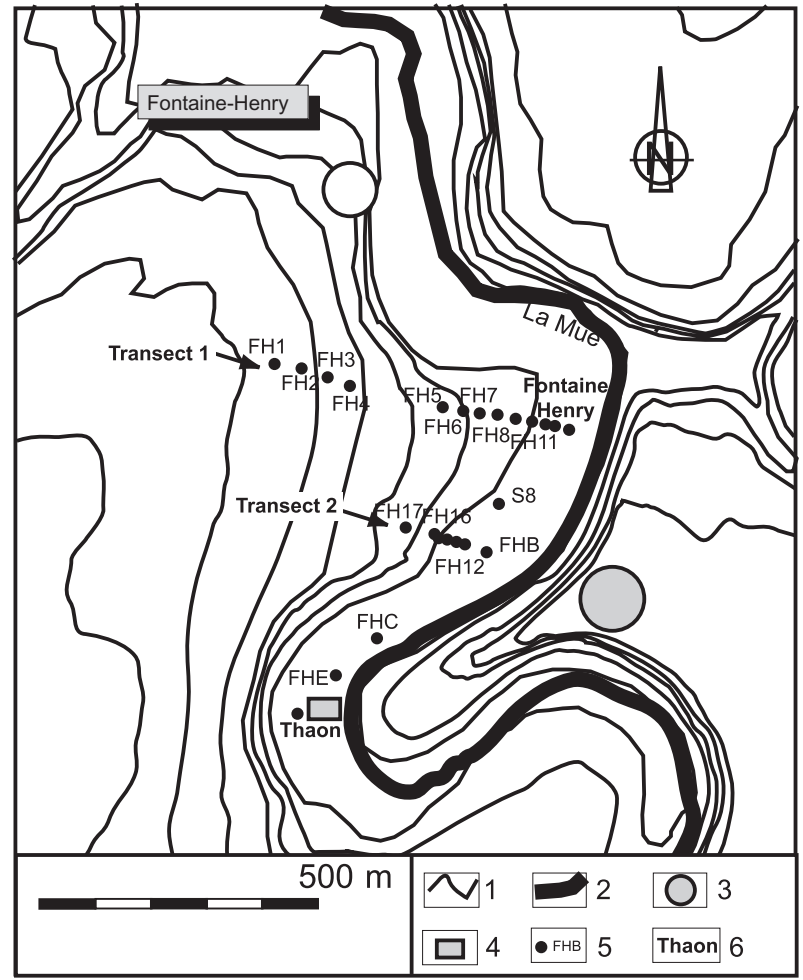

Fig. 8a : Localisation des sondages et des carottages dans le secteur Thaon-Basly-Fontaine-Henry.

1. Courbes de niveau $($ eq. $5 \mathrm{~m})-2$. Ecoulements permanents - 3. Site du Néolithique et de l'Âge du Fer de Basly-la Campagne - 4. Eglise romane de Thaon - 5. Implantation des sondages - 6. Implantation des carottages.

Fig. 8a: Boreholes and Core drillings location in the Thaon-Basly-Fontaine-Henry area.

1. Contour line (eq. $5 \mathrm{~m})$-2. Perenial stream - 3. Neolithic and Iron Age site of Basly-la Campagne-4. Old Church of Thaon-5. Boreholes and shovel ditches -6 . Core drillings. de l'Holocène, au fur et à mesure de l'exhaussement du fond de vallée, les sédiments fluviatiles et palustres sont venus masquer progressivement la base des versants constitués de calcaires en plaquettes. La sédimentation organo-calcaire est recouverte de colluvions limoneuses parfois très grossières et qui comportent localement de nombreux fragments de céramique datés de l'époque gallo-romaine (comm. orale Guy San Juan). En rive convexe (fig. 9b), la couverture limoneuse loessique du Pléniglaciaire, épaisse de 1 à 1,5 mètre sur le plateau, atteint au moins 4,5 mètres sur le versant. Dans le fond de vallée (FH11), ces limons sont surmontés d'un paléosol épais attribuable à l'Atlantique d'après une date de $7740+/-80{ }^{14} \mathrm{C}$ BP. Ce paléosol a ensuite été fossilisé par plus de 2 mètres de colluvions récentes.

\section{Tronçon 5 : le barrage de tuf de Reviers}

Le sondage Re1 de 12 mètres de profondeur dont les 7 premiers ont été carottés permet d'approfondir les premiers résultats obtenus (Clet-Pellerin et al., 1990). Il présente la succession de 5 grandes unités stratigraphiques (fig. 6). La base du sondage est constituée par une argile sableuse gris vert qui devient progressivement plus grise et plastique (U1Re1, Gpe4). U2Re1 voit l'alternance de passées de limons bruns organiques ou de tourbe, épaisses de 5 à $10 \mathrm{~cm}$, et des niveaux de tuf fin gris-beige principalement oncolitique, de 30 à $50 \mathrm{~cm}$ d'épaisseur. Cet horizon débute au tout début de l'Atlantique $\left(7715+/-60{ }^{14} \mathrm{C} \mathrm{BP}\right)$. Il est interrompu par un horizon de limons sableux beiges-jaunes (U3Re1). U4Re1 montre une sédimentation de la fin de

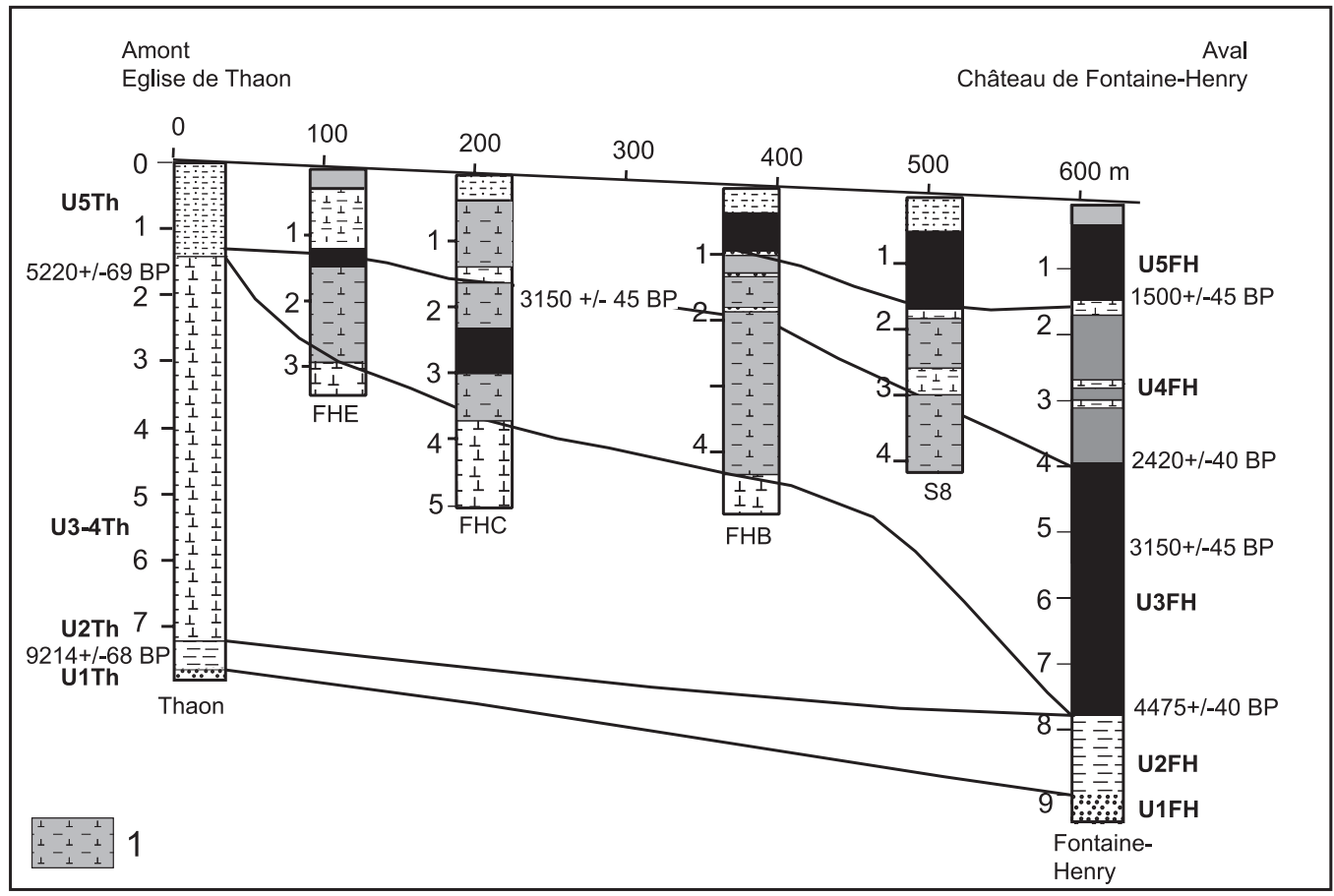

Fig. 8b : Coupe morphostratigraphique longitudinale entre Thaon et Fontaine-Henry. Légende $c f$ fig. 3 et 1 . Limons organo-calcaires.

Fig. 8b: Longitudinal morphostratigraphic cross section from Thaon to Fontaine-Henry. Legend cffig. 3 and 1. Organo-calcareous loam. 


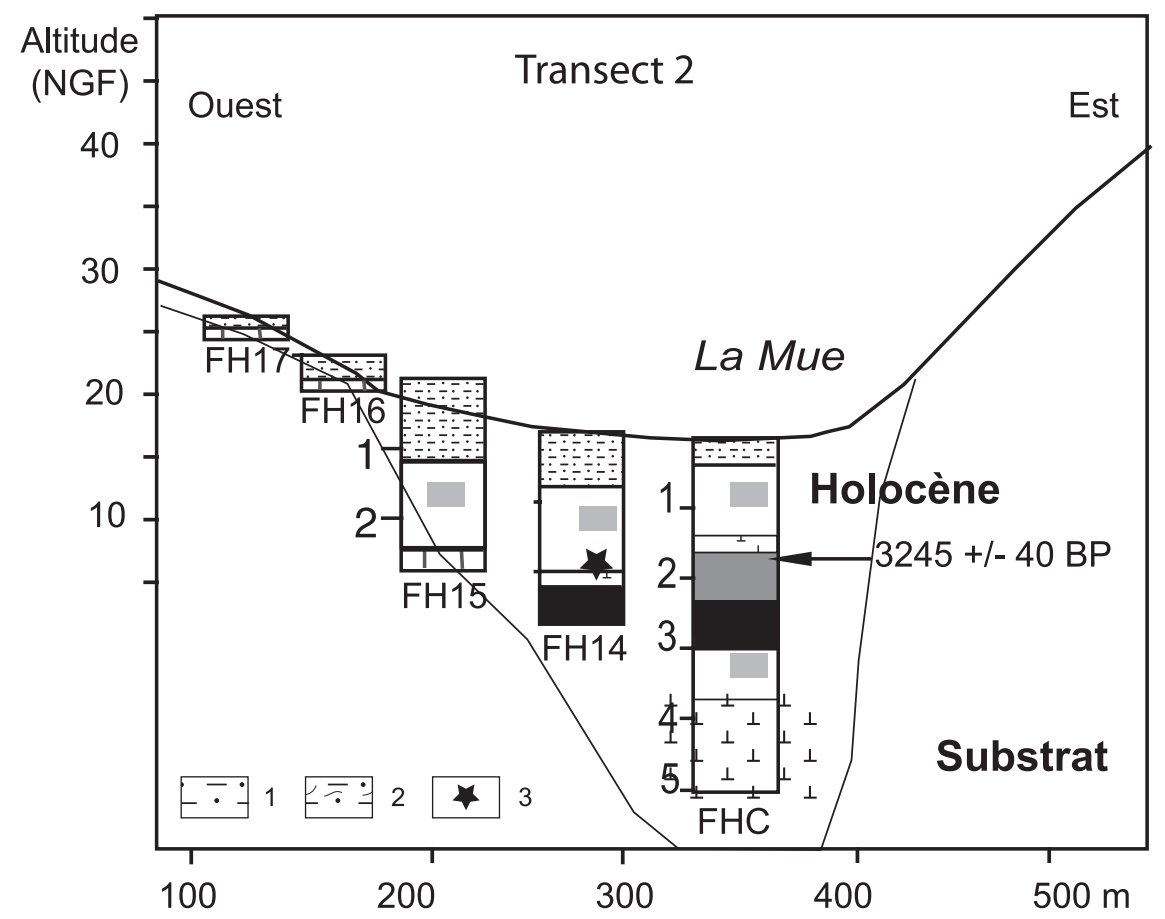

Fig. 9a : Coupes morphostratigraphiques des séquences sédimentaires de la vallée de la Mue à Fontaine-Henry (transect 2).

Légende $c f$. fig. 3 et 1 . Loess - 2. Limons à Pseudo-mycellium - 3. Tessons gallo-romains. L'échelle des altitudes ne s'applique qu'au profil topographique.

Fig. 9a: Morphostratigraphical cross section of the Mue at Fontaine-Henry (transect 2).

Legend cffig. 8 b and 1. Loess-2. Loam with Pseudo-mycellium-3. Gallo-roman potsherds. The altitudinal scale is only valid for the topographic profil.

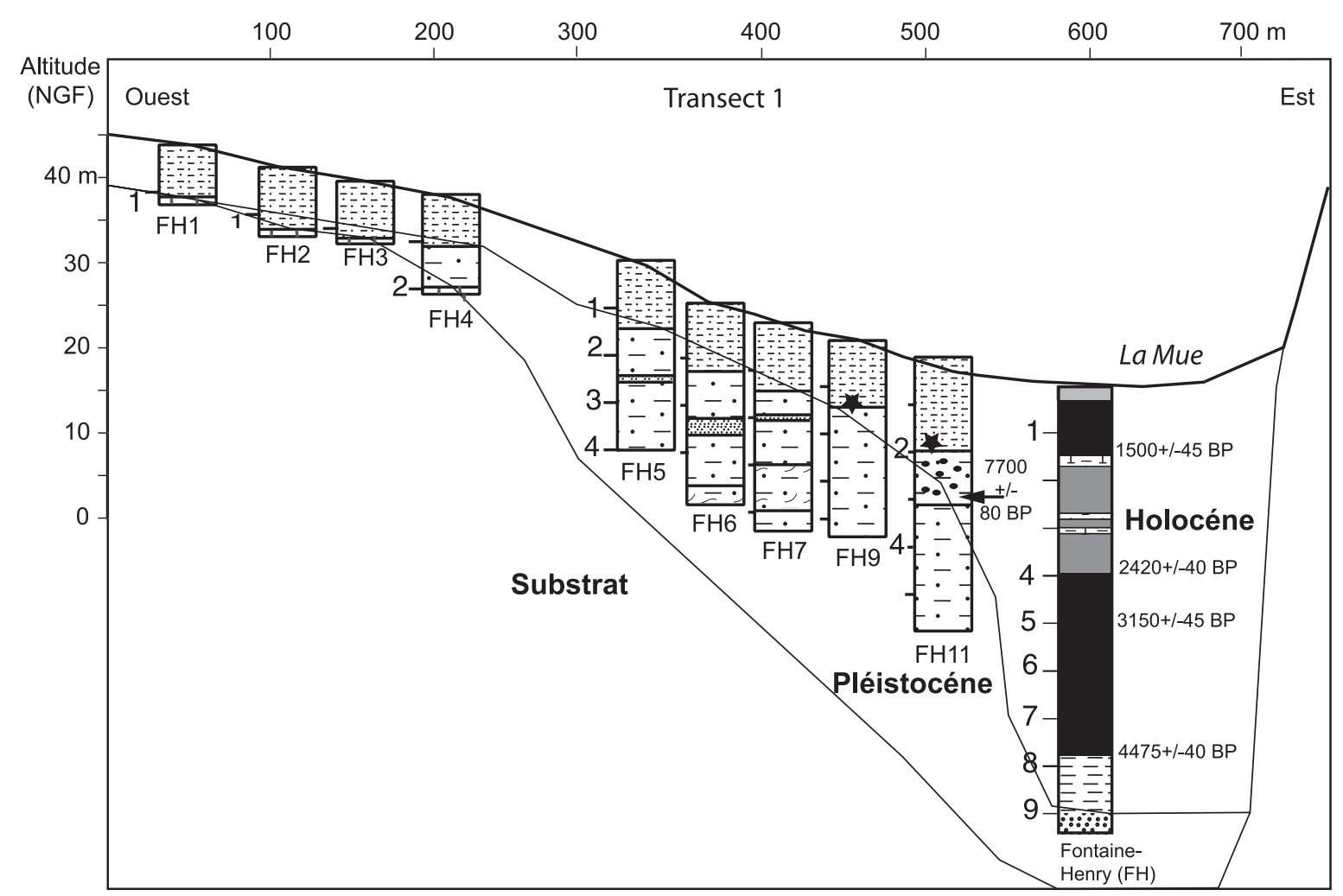

Fig. 9b : Coupes morphostratigraphiques des séquences sédimentaires de la vallée de la Mue à Fontaine-Henry (transect 1$)$. Légende $c f$ fig. 3. Fig. 9b: Morphostratigraphical cross section of the Mue at Fontaine-Henry (transect 1). Legend cf fig. $9 a$. 
l'Atlantique $\left(5989+/-50{ }^{14} \mathrm{C}\right.$ BP au premier tiers de cette unité) où alternent des passées de limons bruns organiques épaisses de 2 à $20 \mathrm{~cm}$ et des niveaux de limons gris tufacés de 5 à $10 \mathrm{~cm}$. U5Re1 forme une puissante unité constituée de tuf blanc grossier interrompue par de rares passées plus organiques (limons tufacés gris organiques). Une date obtenue à la base de cette unité $\left(5315+/-60{ }^{14} \mathrm{C} \mathrm{BP}\right)$ montre qu'elle couvre l'ensemble du Subboréal et probablement une partie du Subatlantique comme le suggèrent les données palynologiques (Clet-Pellerin et al., 1990). L'ensemble est ensuite recouvert par un horizon limoneux (U6Re1).

\section{V - LES ANALYSES PALÉO-BIOLOGIQUES ET BIOSTRATIGRAPHIQUES}

\section{1 - LES ANALYSES POLLINIQUES}

Aux sondages effectués récemment dans la vallée de la Mue (Fontaine-Henry, Reviers, Cairon) sont ajoutés ceux effectués en 1985 à Reviers par J. Pellerin (CletPellerin et al., 1990) et ceux faits à Rots (Clet-Pellerin, 1997), en amont qui, eux, n'ont pas été datés par le ${ }^{14} \mathrm{C}$.

\section{Cairon}

La concentration pollinique est relativement faible si ce n'est au sommet de la tourbe où les valeurs atteignent plus de 14000 grains par gramme de sédiment. Le milieu de sédimentation étant peu remanié, la destruction des grains de pollen a dû se faire in situ. Le diagramme pollinique couvre l'ensemble de la période de l'Atlantique et le passage Atlantique - Subboréal ce qui est confirmé par les datations ${ }^{14} \mathrm{C}$ (fig. 10). Entre $8102+/-58{ }^{14} \mathrm{C}$ BP et $6242+/-49{ }^{14} \mathrm{C} \mathrm{BP}$, le paysage est occupé par les noisetiers et les chênes bordant une zone colonisée par les fougères. Une zone humide est présente mais elle est colonisée par les Composées Tubuliflores (CAI-1a et 1b). Puis, la zone humide avec les Cyperaceae s'accroît et quelques aulnes se développent en bordure précédant l'envahissement du marais par les Phragmites (CAI-2a). Ensuite (CAI-2b), les zones humides sont progressivement envahies par des fougères qui prennent de plus en plus d'importance, sans doute par suite d'un assèchement du milieu et Corylus s'accroît de nouveau. En CAI-3a, le couvert forestier se réduit du fait de la régression des noisetiers et des chênes puis reprend de l'importance après un léger développement des grains de pollens d'Alnus (CAI-3b). La diminution des pourcentages de grains de pollen d'Ulmus pourrait représenter le passage de la période Atlantique au Subboréal pendant laquelle les fougères et les herbacées s' accroissent. Localement, au sommet de la tourbe, les aulnes envahissent le paysage (CAI-4). Dans ce diagramme il n'y a aucune trace de plantes cultivées et les traces d'anthropisation sont discrètes. On peut néanmoins noter la présence constante des plantes rudérales et leur augmentation ainsi que celle des grains de pollen de prairies (CAI-2b/3a) entre 5700-5200 ${ }^{14} \mathrm{C}$ BP environ (4500-4000 cal. av. J.-C.) alors que les pourcentages de pollens de noisetiers et de chênes diminuent notablement. Ces traces d'anthropisation sont à mettre en relation avec la première phase d'occupation du site de la « Pierre Tourneresse » (Néolithique moyen II, Clément-Sauleau et al., 2000) distant de $250 \mathrm{~m}$ environ du fond du vallon du Vey. En effet, les fouilles y ont révélé l'importance de l'élevage et la présence du cheval qui indique également « le développement de biotopes ouverts auxquels cette espèce animale est inféodée » (Arbogast, p. 57 in Ghesquière et Marcigny, sous presse).

Cairon

Analyse M.Clet, 2004

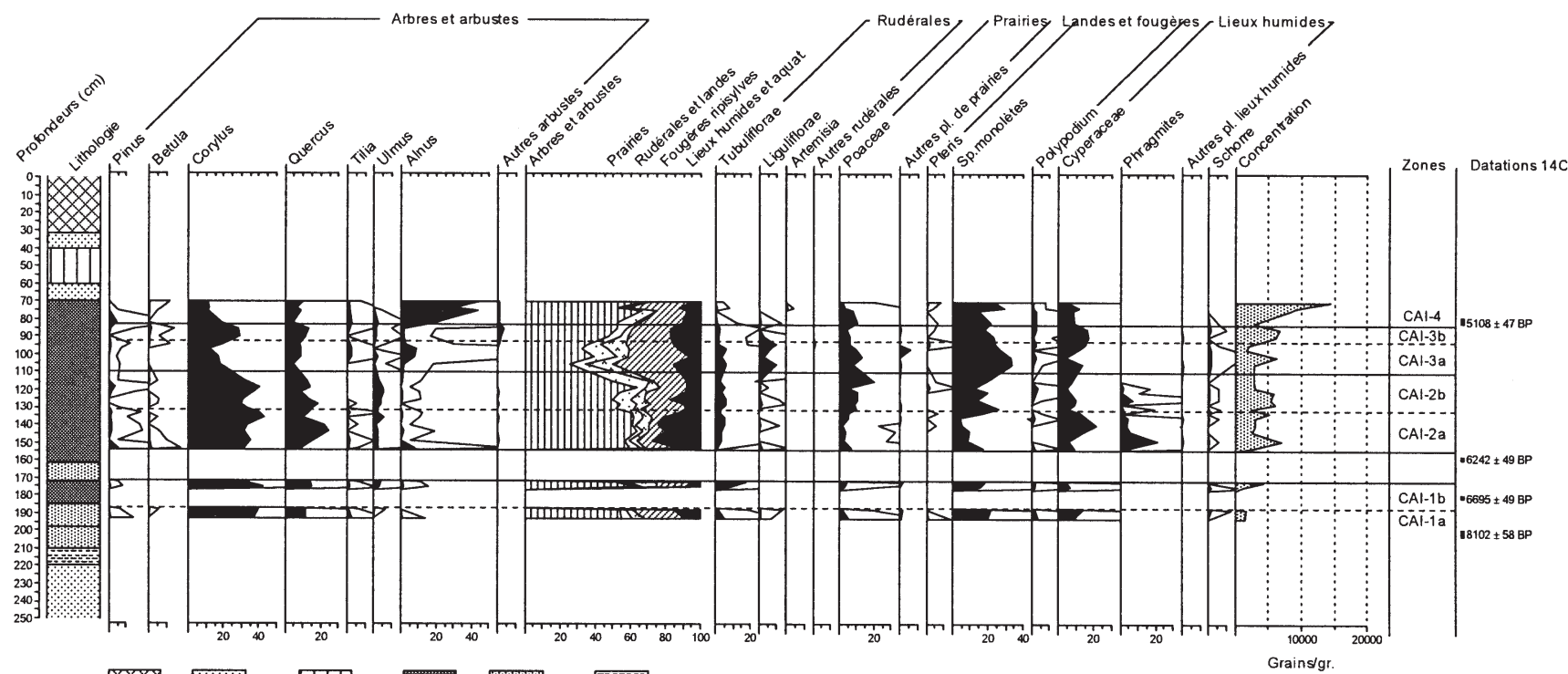

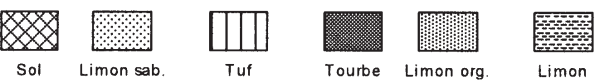

Fig. 10 : Diagramme pollinique de Cairon.

Fig. 10 : Pollen diagram of Cairon. 


\section{Rots}

La concentration pollinique est également faible, le plus souvent inférieure à 5000 grains par gramme de sédiment. Elle indique vraisemblablement la destruction des grains de pollen in situ dans un contexte fluviatile marqué par un balancement saisonnier important de la nappe phréatique et leur remaniement par les écoulements fluviatiles. L'analyse de deux sondages a été effectuée (Clet-Pellerin, 1997) mais la description s'appuiera sur le sondage (Rots 3) qui présente la succession la plus complète. Quatre palynozones principales sont identifiées (fig. 11).

Dans la première (RO3-1) trois phases sont distinguées. Dans le limon tourbeux de la base (RO3-1a), les grains de pollen retrouvés montrent un paysage relativement ouvert ( $36 \%$ de grains de pollen d'arbres et d'arbustes), avec chênes et noisetiers dominants une prairie composée de $24 \%$ de Poaceae et de rudérales (14\% de Composées Liguliflores) dans un milieu relativement humide (11\% de Cyperaceae). Dans la tourbe qui lui succède (RO3-1b), les variations de la végétation sont peu importantes. Le paysage se ferme. Les pourcentages de pollens d'arbres et d'arbustes sont plus élevés par suite de l'accroissement des pourcentages du pollen de Quercus et de Corylus. Tilia, Ulmus, Alnus et Salix sont présents en courbe continue. La prairie et les plantes rudérales sont en légère régression. Les Cypéracées puis les fougères ripisylves sont en augmentation. Au sommet de la tourbe (RO3-1c), la végétation évolue peu même si les pourcentages de pollen d'arbres et d'arbustes ont tendance à diminuer ainsi que ceux de la prairie qui est remplacée par des fougères formant un pic au sommet de la zone. La zone humide tend à s'accroître. Dans la seconde palynozone (RO3-2), les pourcentages de pollens d'Alnus, de Corylus et de Quercus augmentent brusquement après le retrait des fougères. La prairie et les plantes rudérales après un déclin reprennent de l'importance au sommet de la zone. Ces zones sont attribuables à l'Atlantique et montrent des signes d'anthropisation à la fin de la période (RO3-2b) marquée par l'apparition des plantes cultivées et l'augmentation des plantes rudérales. Elles sont peutêtre à mettre en relation avec la vaste nécropole néolithique de Rots, qui compte une dizaine de longs monuments de plusieurs dizaines de mètres attribuables à la culture de Cerny (4700-4200 cal. av. J.-C.) (Desloges, 1997). Cette nécropole, qui devait être liée à plusieurs zones habitées synchrones, couvre une quinzaine d'hectares.

Après une passée de limons tufacés, la végétation change (RO3-3). Le paysage est ouvert, les pourcentages de pollen d'arbres et d' arbustes ont fortement diminué et les plantes cultivées (céréales), les rudérales et les plantes de prairies présentent une courbe continue marquant un paysage profondément humanisé dans le fond de vallée et au-delà. La zone (RO3-3b, 3c) est caractérisée par la réduction des zones humides alors qu'une prairie accompagnée de plantes rudérales s'installe de nouveau. L'apparition de Juglans (noyer) à $200 \mathrm{~cm}$ (RO3-3b) permet d'attribuer un âge historique à cette zone. Il est en effet courant d'admettre que le noyer a été introduit dans la France du nord-ouest par les Romains. Dans la partie supérieure du sondage (RO3-4a à 4c), les plantes cultivées perdurent mais les pourcentages de pollen d'arbres et d'arbustes diminuent encore. La prairie devient très humide permettant le développement brutal des Cyperaceae bientôt remplacées par les Composées Liguliflores. Au sommet, les pourcentages de Pinus dépassent $14 \%$ et permettent d'attribuer à cette zone un âge post-XVII siècle car ces arbres ont sans doute été plantés au $\mathrm{XVIII}^{\mathrm{e}}$ ou au XIX ${ }^{\mathrm{e}}$ siècle comme c'est souvent le cas dans les châteaux normands.

Rots, parc du château, sondage 3

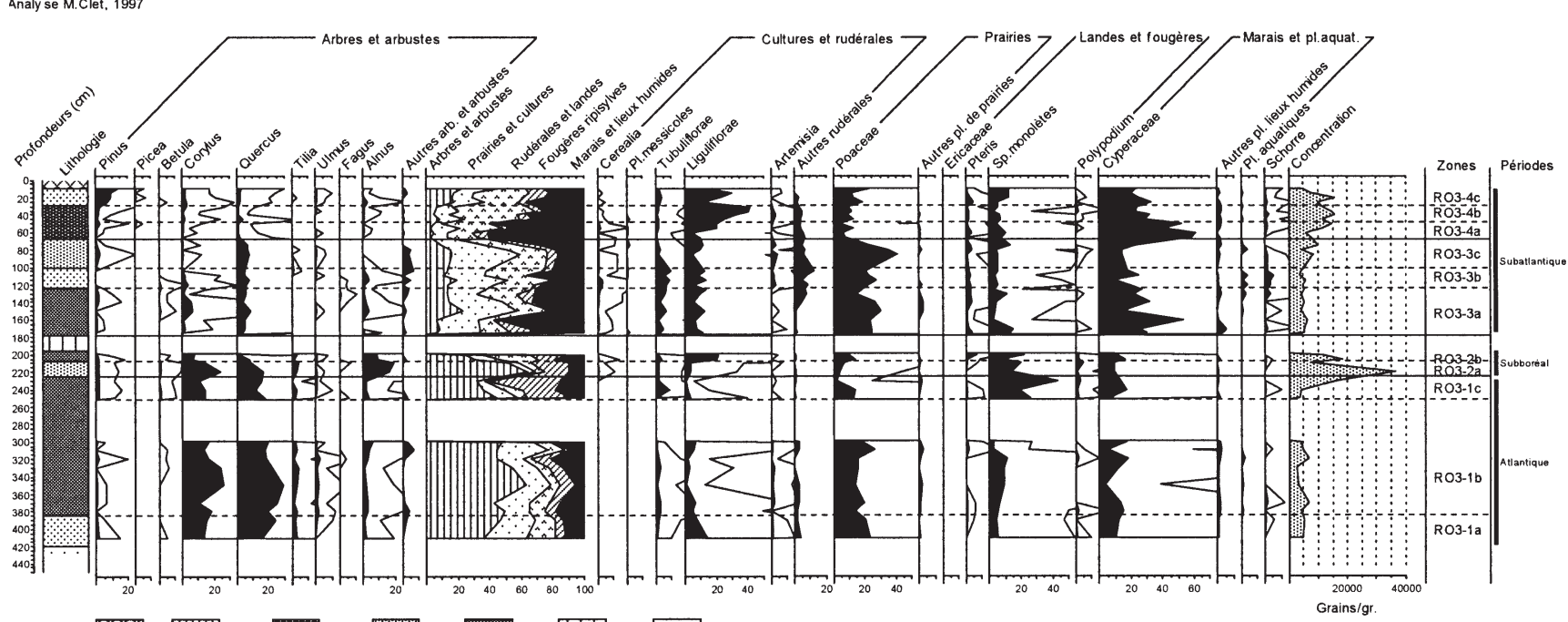

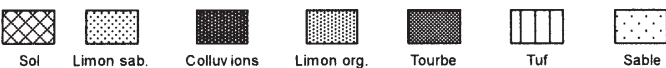

Fig. 11 : Diagramme pollinique de Rots3. Fig. 11: Pollen diagram of Rots3. 


\section{Fontaine-Henry}

La concentration pollinique très faible, le plus souvent inférieure à 5000 grains/gramme de sédiment, indique vraisemblablement la destruction des grains de pollen in situ ou leur remaniement à mettre en relation avec le contexte fluviatile local. En effet, celui-ci est marqué par un balancement saisonnier important de la nappe phréatique favorisant le développement d'une végétation arbustive et par des écoulements remaniant les sédiments. Cela explique les difficultés rencontrées pour établir la chronologie du sondage et le rejet de 2 datations obtenues sur la matière organique totale vraisemblablement pour cause de remaniement de matière organique ancienne et de contamination par des racines plus récentes (tableau 1).

Le sondage de Fontaine-Henry traversant deux épisodes tourbeux couvre la plus grande partie du Subboréal et le Subatlantique (fig. 12). Les datations ${ }^{14} \mathrm{C}$ obtenues, entre $4475 \pm 40{ }^{14} \mathrm{C}$ BP vers $8 \mathrm{~m}$ de profondeur et $1500 \pm 45{ }^{14} \mathrm{C}$ BP vers $1,5 \mathrm{~m}$ le confirment. Dans l'ensemble la végétation est dominée par les herbacées et les spores de fougères. Les pourcentages de grains de pollen d'arbres et d'arbustes dépassent rarement $40 \%$. Les zones héliophiles en bordure des espaces forestiers avec Quercus, Corylus et Alnus et bordant un marais, sont colonisées par les fougères (FH-1a à 1c). Des prairies avec quelques plantes rudérales sont également présentes. Puis progressivement (FH-2a à 2c), les zones humides s'accroissent et postérieurement à $2400{ }^{14} \mathrm{C} \mathrm{BP}$, les pourcentages de grains de pollen de plantes aquatiques augmentent, plantes indicatrices d'un espace d'eau libre dans le paysage ( $\mathrm{FH}-2 \mathrm{c}$ à $3 \mathrm{a})$. Pendant la période la plus récente, entre $1500{ }^{14} \mathrm{C} \mathrm{BP}$ et $300{ }^{14} \mathrm{C}$ BP, les zones humides s'accroissent de plus en plus remplaçant progressivement les fougères. Fagus (hêtre) est présent sur l'ensemble du diagramme.

Au cours du Néolithique, la présence des plantes de prairies, des plantes rudérales et adventices témoigne d'une anthropisation. Celle-ci est en partie contemporaine de l'occupation de l'éperon barré de Basly-La Campagne au cours du Néolithique final (autour de 2600 av J.-C., San Juan, 2003) qui domine le lieu de sondage. Les plantes cultivées apparaissent au Bronze Ancien (FH-2a) vers $3400{ }^{14} \mathrm{C}$ BP environ (1700 av. J.-C.) au cours d'une époque mal renseignée localement. A la fin de l'âge du Bronze et au premier Âge du Fer, la végétation forestière diminue alors que se développe à Basly-La Campagne un habitat fortifié du $\mathrm{VI}^{\mathrm{e}}$ siècle avant notre ère (San Juan, 2004). Cette situation ne connaît pas d'évolution notable au cours de la période de La Tène malgré l'importance de l'occupation attestée dans cette partie du bassin versant de la Mue (San Juan et al., 1999). Au cours de l'Antiquité, on

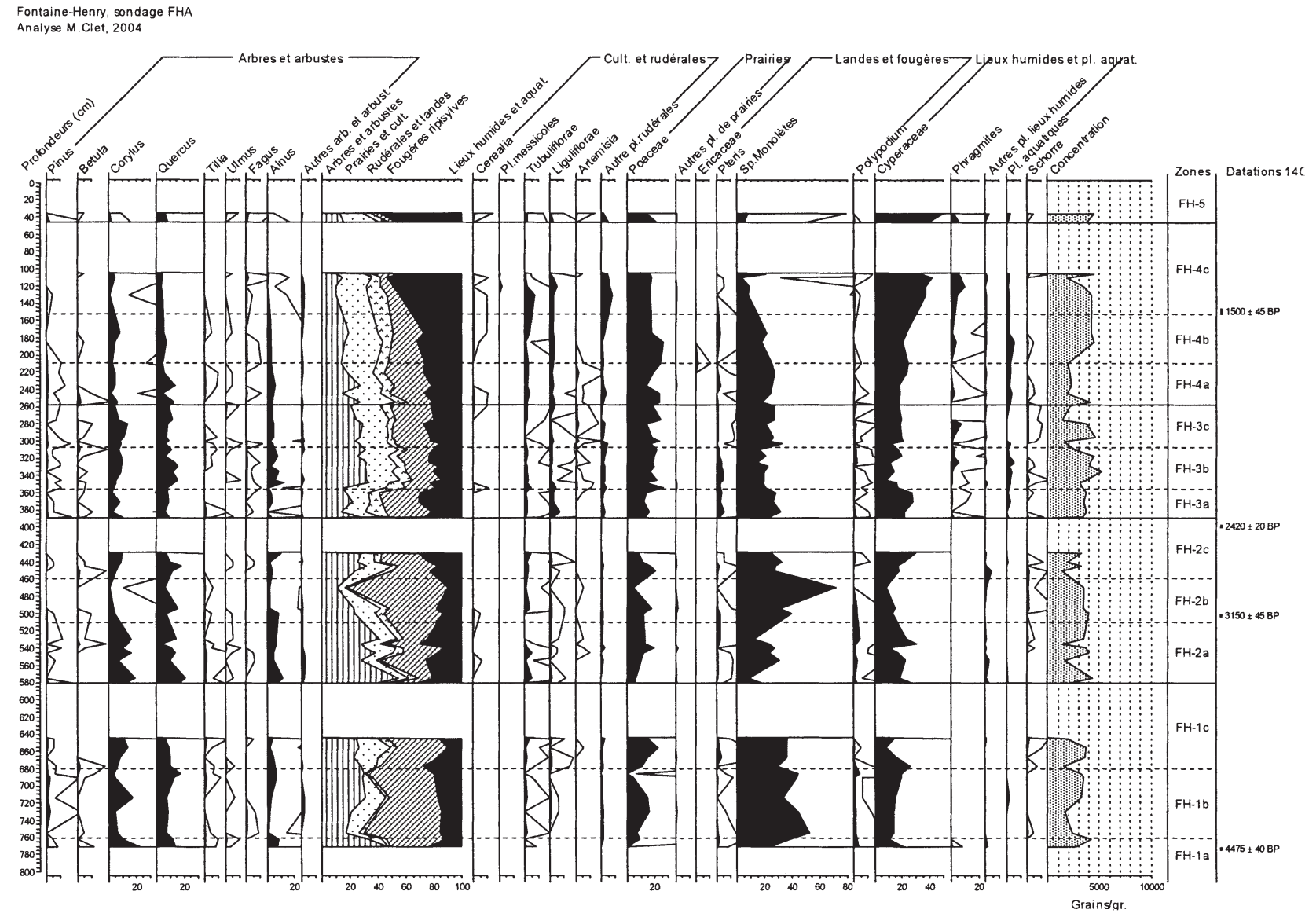

Fig. 12 : Diagramme pollinique de Fontaine-Henry (FH). Fig. 12: Pollen diagram of Fontaine-Henry $(\mathrm{FH})$. 
observe une période de légère reprise des espaces boisés dans le fond de vallée et sur les versants dans un environnement où les espaces forestiers sont néanmoins devenus résiduels. Les céréales présentent une courbe continue à partir de $1500+/-45{ }^{14} \mathrm{C} \mathrm{BP}$ environ alors que les plantes adventices et rudérales atteignent des niveaux jamais obtenus auparavant dans un contexte où l'implantation humaine dans le fond de vallée est attestée à proximité par les fouilles de la Vieille Eglise de Thaon (Delahaye et Niel, 2004). Cette situation perdure au cours de l'époque médiévale.

\section{2 - L'ANALYSE MALACOLOGIQUE DU TUF DE THAON}

Elle repose sur l'analyse de 30 échantillons, dont le volume varie de 300 à 900 grammes, prélevés en continu le long du carottage de Thaon. Le seuil idéal de représentativité d'un assemblage malacologique se situe aux alentours de 250 individus récoltés dans des prélèvements d'environ 5 litres de sédiments en moyenne (Evans, 1972). Dans le cas d'un échantillonnage sur carottage comme à Thaon la quantité de sédiment disponible limite a priori la fiabilité de l'analyse malacologique. L'expérience a cependant montré qu'en contexte fluviatile les malacocénoses sont souvent très abondantes et dépassent le seuil quantitatif théorique même dans des échantillons de faible volume, rendant ainsi possible des analyses environnementales pertinentes à partir du traitement de séquences carottées (Limondin-Lozouet et Antoine, 2001).

À Thaon la variabilité quantitative des malacocénoses est plus liée à la lithologie qu'au poids des échantillons (Fig. 13). La distribution des effectifs malacologiques souligne trois phases favorables aux mollusques dans la série de Thaon. La première est située à la base de la série, la seconde entre 5,5 et 5,7 $\mathrm{m}$ de profondeur, la troisième qui est aussi la plus développée concerne les deux mètres supérieurs du sondage. Ces phases correspondent dans la lithologie à des niveaux de granulométrie fine et plus riches en matière organique. La conjonction des données lithologiques et malacologiques (fig. 7, 13) met en évidence des épisodes plus stables à sédimentation ralentie, plus favorable à l'installation du couvert végétal et à la pérennisation des communautés malacologiques. A l'inverse les épisodes à malacofaunes pauvres sont corrélables à des dépôts essentiellement carbonatés, le plus souvent grossiers dominés par des concrétions de type oncolithiques, très probablement liés à une activité plus intense du cours d'eau donnant lieu à des accumulations sédimentaires rapides.

La représentation des malacocénoses sous forme de spectres malacologiques (Fig. 14) selon la méthode de Puisségur (1976) permet de conforter l'interprétation tirée de la distribution des effectifs et de définir un premier schéma des variations environnementales. Tous les échantillons ont fait l'objet de calculs de pourcentages cependant les communautés pauvres en
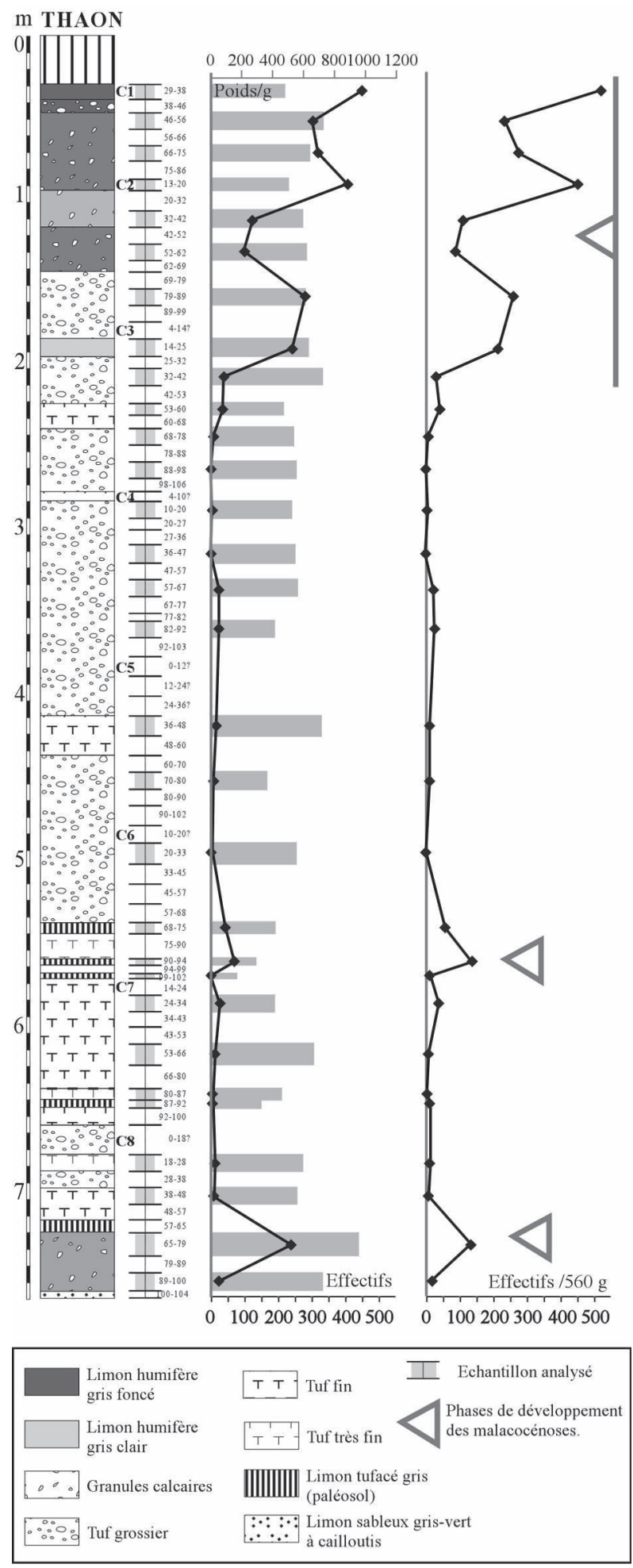

Fig. 13 : Courbes des effectifs malacologiques du tuf de Thaon. A gauche la première courbe rend compte du nombre de coquilles récoltées en regard du poids des échantillons (histogrammes grisés). Sur la seconde courbe, le poids a été standardisé en fonction de la moyenne $(560 \mathrm{~g})$. Si certaines variations d'effectifs sont corrélatives des changements de poids des échantillons, le rapport "effectif/poids moyen" exprimé sur la deuxième courbe ne fait pas ressortir d'importantes différences par rapport à la première. Fig. 13: Thaon number of shells curves.

The first curve has been drawn versus samples weight (grey areas). The second curve has been built for an average sample weight $(560 \mathrm{~g})$. Some variations in number of shells are linked to sample weight, but no dramatic change can be observed between both curves. 
individus dont la représentativité est discutable sont individualisées par un fond grisé (Fig. 14).

À la base de la série la première malacozone présente un assemblage au sein duquel $35 \%$ des effectifs sont répartis entre les groupes 1 et 2 , représentatifs des milieux fermés, ainsi que le groupe 8 exclusivement représenté par Carychium tridentatum, espèce caractéristique des humus forestiers (Kerney et al. 1983). Les $38 \%$ du groupe 5 sont essentiellement dus à l'espèce Vallonia costata, connue pour coloniser fréquemment les habitats à végétation fermée (Kerney et al. 1983). Les mésophiles (G7) comptent pour $20 \%$ de la population malacologique. Les groupes liés au domaine aquatique (palustres et aquatiques) sont anecdotiques, révélant un milieu terrestre bien drainé. L'ensemble indique un milieu en mosaïque où des zones herbeuses côtoient des aires à végétation plus fournie de type taillis, buissons et bosquets. Ces éléments restent présents jusqu'au sommet de la zone, vers $5,5 \mathrm{~m}$ de profondeur, où les assemblages présentent une tendance vers une ouverture un peu plus prononcée du paysage.

Durant la seconde malacozone (entre 5,5 et 2,3 m environ), les assemblages sont pauvres. Les mollusques aquatiques sont plus fréquemment représentés, témoignant d'une dynamique alluviale plus intense dans le fond de vallée.

À partir de $2 \mathrm{~m}$ les effectifs malacologiques augmentent à nouveau et resteront proches ou au-delà du seuil de représentativité jusqu'au sommet de la séquence. De 2 à 1,5 m, la malacozone 3 rassemble des assemblages dominés par les mollusques de milieu ouvert (G5 toujours représenté presque exclusivement par $V$. costata) et les mésophiles (G7), les espèces de biotopes fermés (G1, G2 et C. tridentatum) sont bien présentes (30\%).

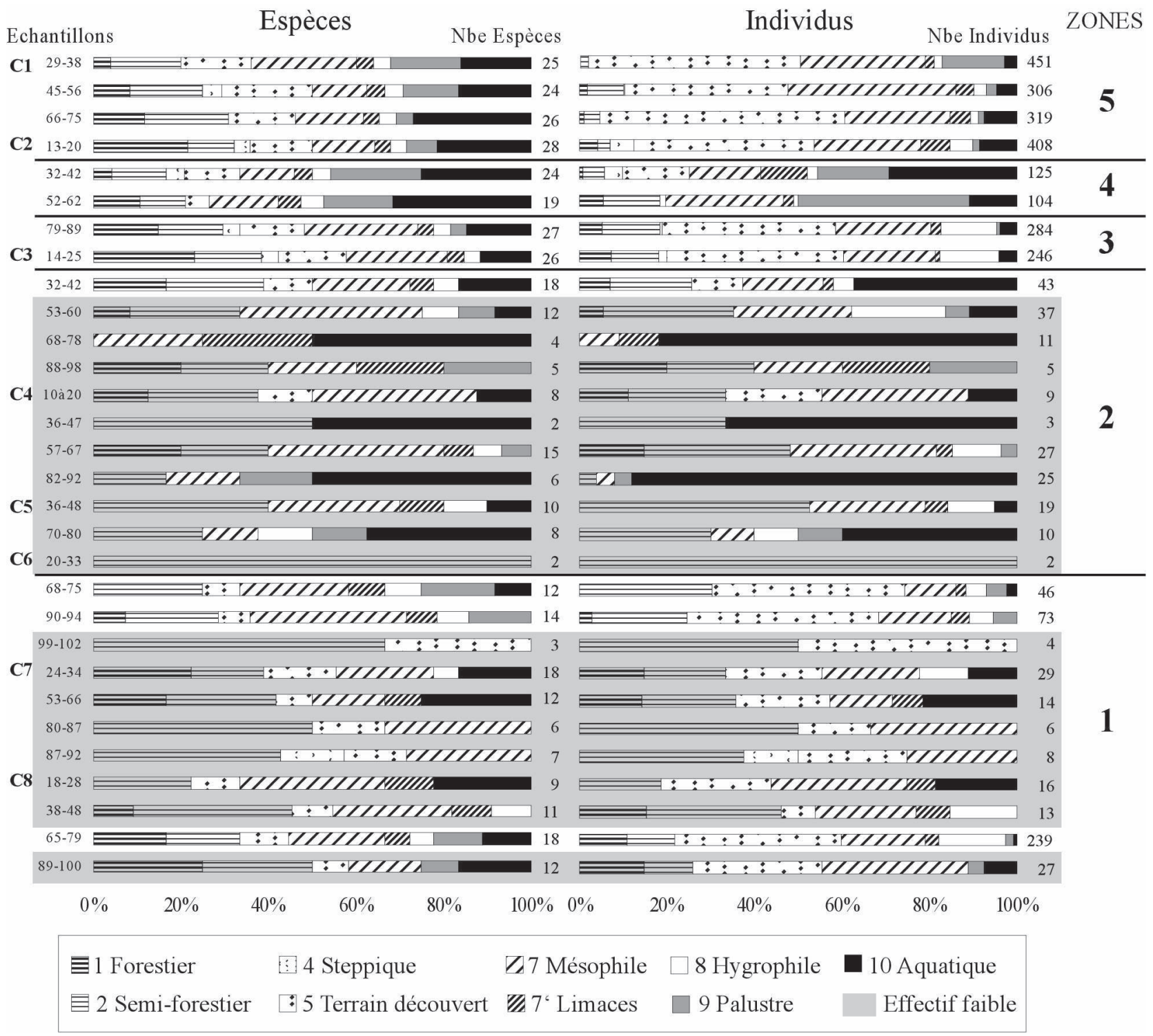

Fig. 14 : Répartition en pourcentages des groupes écologiques représentés par les malacofaunes de Thaon en fonction du nombre d'espèces et du nombre d'individus contenus dans chaque échantillon.

Fig. 14: Malacological percentages of ecological groups occurrences within Thaon assemblages calculated from total number of species and total number of shells in each sample. 
L'ensemble évoque un paysage en mosaïque (prairie à buissons et bosquets) semblable à celui décrit à la base de la séquence. L'apparition de quelques individus de Helicella itala, espèce du groupe 4 des steppiques, dénote l'existence de microhabitats plus secs.

De 1,3 à $1 \mathrm{~m}$ (malacozone 4), les mollusques de terrain ouvert (G5) régressent fortement tandis que les espèces liées au domaine aquatique (G9 et G 10) se développent de manière très sensible. L'augmentation des effectifs et la diversification des espèces palustres en particulier (G9) révèlent la pérennité annuelle d'un biotope aquatique et impliquent l'installation d'un milieu marécageux.

Dans les quatre échantillons sommitaux (malacozone 5) ces espèces palustres connaissent une régression importante tandis que se développent à nouveau les mollusques du groupe G5 représentatifs des milieux ouverts. Cependant $V$. costata, précédemment majoritaire, se trouve remplacée par ses congénères $V \cdot$ pulchella et $V$. excentrica. Cette variation au sein du développement des Vallonia révèle un milieu plus ouvert que précédemment, la mosaïque herbeuse à taillis et buissons est remplacée par un biotope plus homogène de type prairie, la couverture végétale au sol reste dense mais les zones à végétation plus haute se raréfient.

Les faunes malacologiques peuvent fournir des indications biochronologiques précises. Ainsi les études sur la période Tardiglaciaire ont montré que chaque phase climatique était caractérisée par des associations et/ou des espèces particulières dont les occurrences sont synchrones à travers l'ensemble du territoire nordouest européen (Limondin-Lozouet, 2002). Ce type de référentiel est construit progressivement sur la base de nombreuses analyses, d'abord au niveau régional, puis les comparaisons sont exercées à des échelles plus importantes. Dans la moitié Nord de la France, pour la période Holocène, la constitution des références rendant compte des variations malacologiques en est encore à ses débuts. Cependant une première série bien datée, couvrant la première moitié de l'interglaciaire a été étudiée dans la vallée de la Laize (Saint-Germainle-Vasson in Limondin-Lozouet et Preece, 2004 ; Limondin-Lozouet et al., ce volume). Cette succession malacologique est issue d'un dépôt de tuf de source développé sur un versant. La proximité géographique et la similitude lithologique offrent une bonne base pour la comparaison des successions de Thaon et de Saint Germain-le-Vasson.

Le site de Saint-Germain-le-Vasson a livré une série tufacée d'environ 10 mètres d'épaisseur qui s'est déposée entre 9700 et $4200{ }^{14} \mathrm{C} \mathrm{BP}$. Après une première phase de paysage relativement ouvert, les malacofaunes indiquent une évolution rapide vers la fermeture et la densification du couvert végétal qui persisteront jusqu'au sommet de la séquence. Les occurrences et disparitions de plusieurs espèces repères jalonnent cette succession de malacofaunes forestières, elles soulignent des variations environnementales surtout liées à l'humidité et constituent des marqueurs chronologiques. L'évolution environnementale locale enregistrée par les malacocénoses de la série de l'église de Thaon est différente, elle rend compte d'un environnement de fond de vallée à paysage plutôt ouvert au sein duquel la couverture forestière ne joue qu'un rôle secondaire. Cependant plusieurs espèces repères identifiées à Saint-Germain-le-Vasson sont présentes à Thaon et permettent de proposer des éléments biochronologiques.

Quatre de ces espèces (Discus rotundatus, Pomatias elegans, Hygromia limbata, Acicula fusca) apparaissent à Thaon dans le même ordre qu'à Saint Germain-le-Vasson où elles démarrent respectivement à 9000, 8500, 6500 et $5400{ }^{14} \mathrm{C} \mathrm{BP}$ (Fig. 15). Ces datations constituent, en l'état actuel des connaissances, des âges maximum pour la région, les occurrences de ces taxons à Thaon peuvent être plus récentes. Dans tous les cas ces espèces perdurent à Saint Germain-le-Vasson jusqu'au sommet de la série et, bien que parfois rares, elles sont encore présentes actuellement en Normandie. Les deux datations

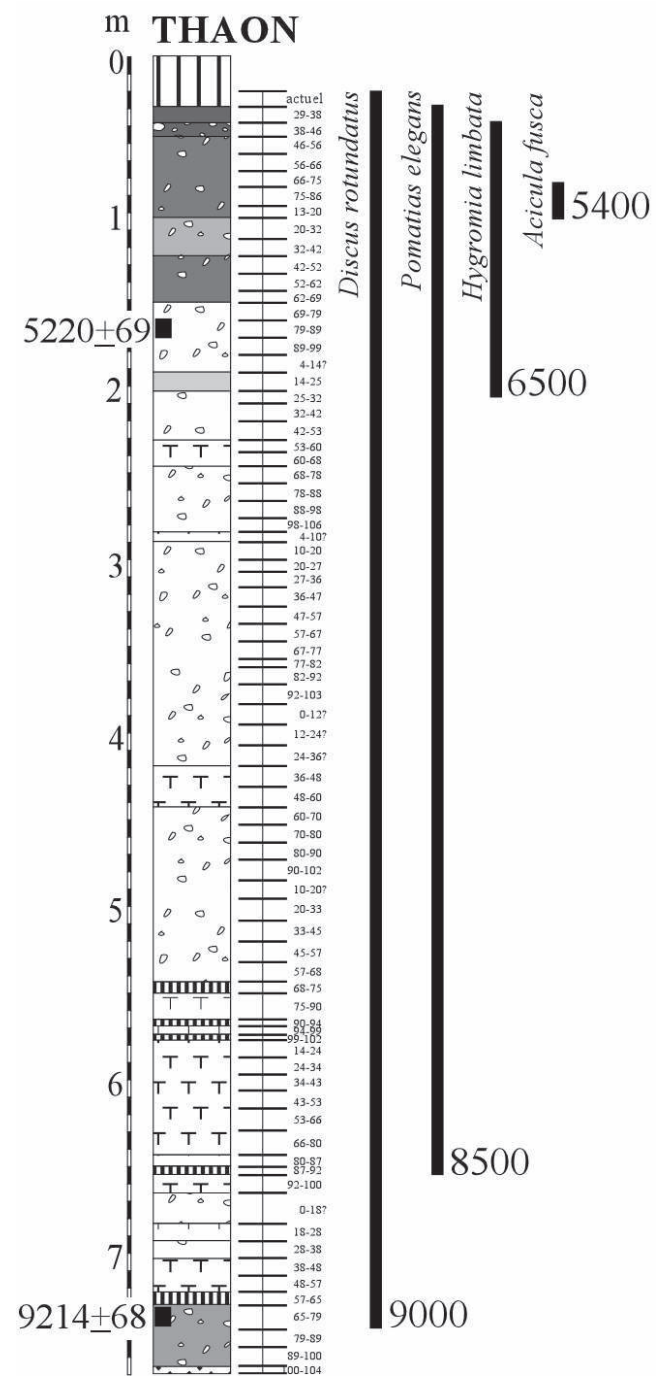

Fig. 15 : Occurrence des espèces marqueurs biostratigraphiques dans la séquence de Thaon. Les dates maximum de leur apparition régionale, identifiées sur le site de Saint-Germain-le-Vasson, sont mentionnées en années BP.

Fig. 15: Molluscan biostratigraphy of Thaon sequence. Dates of maximum regional occurrences of these species, identified at Saint-Germainle-Vasson, are given in yr BP. 
radiocarbone obtenues postérieurement s'intègrent parfaitement au schéma biochronologique basé sur le référentiel malacologique (Fig. 15).

\section{VI - CHRONOSTRATIGRAPHIE HOLOCÈNE DES ENVIRONNEMENTS DE FOND DE VALLÉE}

Le découpage longitudinal de la vallée de la Mue en tronçons morpho-sédimentaires aux caractéristiques différentes rend difficile la constitution d'une chronostratigraphie d'ensemble car les variations spatiales des dynamiques hydrosédimentaires (fig. 16) viennent contrecarrer l'analyse des variations temporelles. Les quelques transects réalisés dans le fond de vallée montrent, en revanche, une faible variation latérale des faciès sédimentaires qui est à relier à la modestie et la régularité des débits des cours d'eau directement alimentés par l'aquifère du Bathonien. Dans ce contexte, une analyse attentive des sondages et des carottages permet de dégager sept phases dans le remplissage holocène du fond de vallée (fig. 16).

\section{1 - FIN DU PLÉISTOCÈNE ET DÉBUT DE L'HOLOCÈNE}

La faiblesse de la sédimentation enregistrée pour la fin du Pléistocène et le début de l'Holocène dans la vallée de la Mue confirme les observations réalisées dans l'ensemble des vallées normandes. Dans l'axe de la vallée, une séquence détritique constituée de graviers calcaires $(\mathrm{FH})$, de sables $(\mathrm{R} 01,3$; Re1) ou de limons sableux à gravillons qui prennent une teinte verdâtre (Thaon) repose sur le substrat. Cette séquence n'a jamais pu être directement datée. Mais les écoulements à forte compétence qu'elle suppose indiquent probablement une mise en place à la fin du Weichsélien. L'absence de sédimentation différenciée attribuable au Tardiglaciaire à l'opposé de nombreuses observations réalisées dans le centre, le nord et l'est du Bassin de Paris (Antoine et al., 2000, 2003 ; Pastre et al., 2000, 2003a) s'explique par la situation de tête de bassin versant sollicitée par un niveau de base relativement proche mais beaucoup plus bas que l'actuel. Cette situation l'emporte sur l'impact des fluctuations climatiques attestées dans la plupart des vallées du bassin de Paris (Antoine et al., 2000, 2003 ; Pastre et al., 2000, 2003a). La dynamique reste vraisemblablement au creusement modéré jusqu'au début du Préboréal. À Fontaine-Henry, l'emboîtement de sédiments organiques du Subboréal dans les limons éoliens weichséliens traduit la faiblesse de l'érosion latérale du cours d'eau qui n'a pas purgé l'ensemble des limons loessiques accumulés sur ce versant et dans le fond de vallée.

\section{2 - FIN DU PRÉBORÉAL ET BORÉAL $\left(9500-8000{ }^{14} \mathrm{C} \mathrm{BP}\right)$}

La grave weichsélienne est ensuite recouverte par des limons argileux gris (S6, S26, Cairon, Re1) plus ou moins sableux (RO1, 3) ou gravillonneux (Thaon, FH). Ils ont pu être datés à leur sommet à Thaon (9214 +/$68{ }^{14} \mathrm{C}$ BP) mais ils peuvent également être calés par deux datations obtenues sur l'unité immédiatement supérieure qui donnent un âge ante-quem : $8102+/-58$ ${ }^{14} \mathrm{C} \mathrm{BP}$, à Cairon, et $7715+/-60{ }^{14} \mathrm{C} \mathrm{BP}$ à Reviers. Cette séquence est donc attribuable à la fin du Préboréal et au début du Boréal. Elle est contemporaine des premières phases de remplissage sédimentaire observées dans la plupart des basses vallées normandes (Huault, 1972; Clet-Pellerin et al., 1977 ; Lesueur et al., 2003, CletPellerin et Verron, 2004). La remontée du niveau de base, l'érosion des limons loessiques weichséliens et leur mise en place dans le fond de vallée par débordement sont sans doute à l'origine de cette sédimentation. L'écoulement chenalisé de la Mue est attesté localement (Thaon) par les analyses malacologiques qui montrent dans le fond de vallée un milieu terrestre bien drainé au sein d'un environnement caractérisé par une végétation en mosaïque où des zones herbeuses côtoient des espaces boisés.

Vers la fin de la période à Thaon se développe une sédimentation tufacée à passées limoneuses qui se poursuit jusque vers $8000{ }^{14} \mathrm{C}$ BP d'après les successions malacologiques observées et leur comparaison avec celles bien documentées de St Germain-le Vasson (Limondin-Lozouet et Preece, 2004). Le fond de vallée reste bien drainé avec des malacofaunes proches de celles de la période précédente.

A cette époque les premiers témoins archéologiques de la fréquentation humaine de la vallée commencent à être enregistrés. Plusieurs silex taillés datés du Mésolithique moyen et final ont été découverts sur les communes de Reviers, Cairon et Rots (prospection de C. Moulin et J. Barge). Il s'agit principalement d'armatures de flèches perdues par ces premières populations de chasseurs cueilleurs mais les impacts anthropiques sur les milieux de fond de vallée ne sont pas détectés.

\section{3 - ATLANTIQUE ANCIEN (8000-6000 ${ }^{14} \mathrm{C}$ BP)}

La sédimentation tufacée de Thaon est le premier témoignage du développement d'une sédimentation carbonatée marquée par de régulières interruptions par des limons gris tufacés plus ou moins organiques (Cairon) ou des passées tourbeuses (Reviers) qui gagne une partie du fond de vallée. A Cairon, cette sédimentation se développe entre $6695+/-49{ }^{14} \mathrm{C}$ BP et $6242+/-49$ ${ }^{14} \mathrm{C} \mathrm{BP}$ alors qu'à Reviers, elle se développe à partir de $7715+/-60{ }^{14} \mathrm{C}$ BP et avant $5989+/-50{ }^{14} \mathrm{C}$ BP. Cette séquence organo-calcaire modeste caractérise la première moitié de l'Atlantique. Elle témoigne d'un net ralentissement des transferts sédimentaires détritiques et d'une prédominance de la charge dissoute carbonatée. À Thaon, le mode de construction de l'édifice tufacé change. Une sédimentation fluviatile oncolithique accompagnée de mollusques aquatiques se développe sur cette section à pente plus forte. L'ensemble de ces mutations s'explique par une augmentation du niveau de l'aquifère du Bathonien responsable 


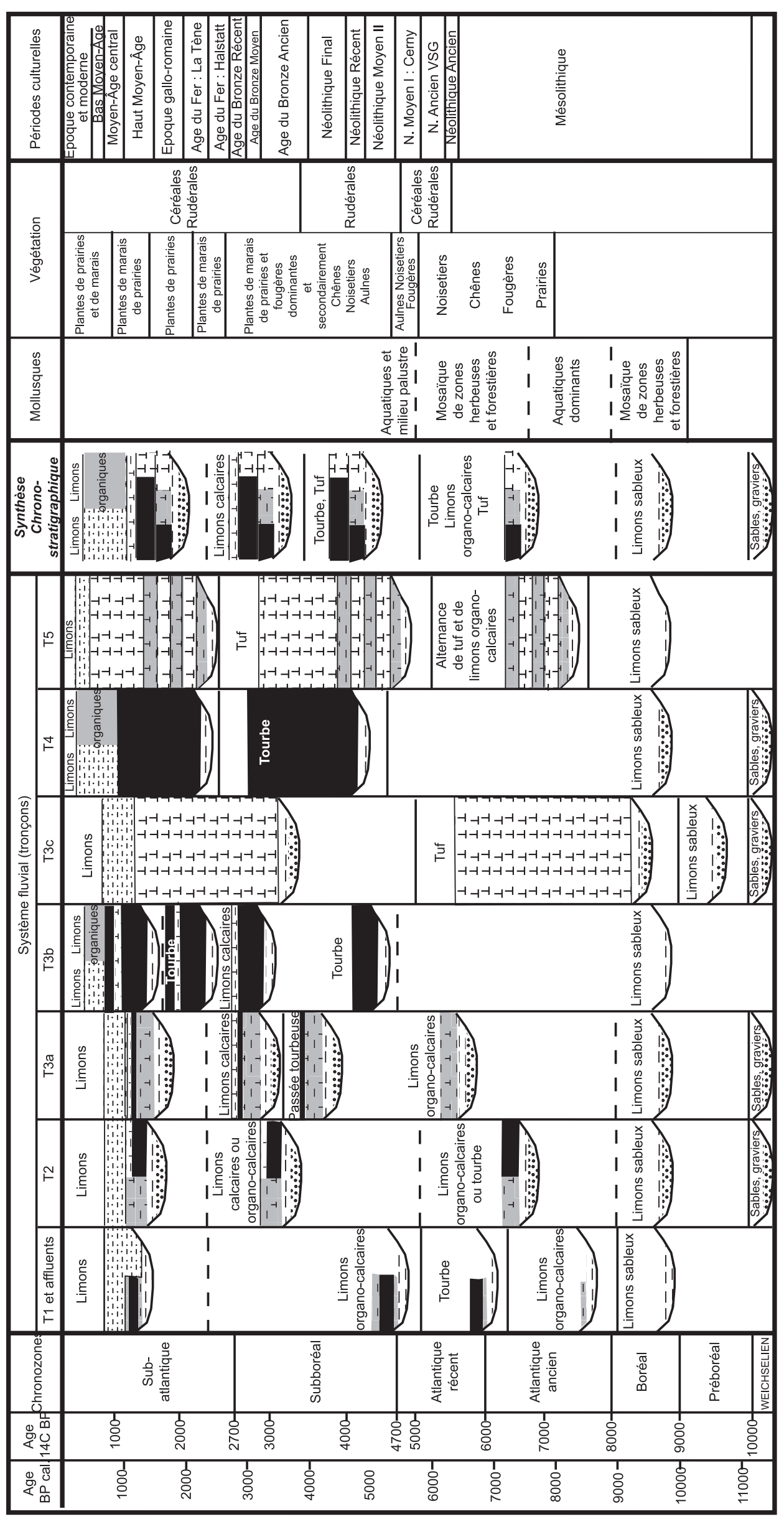

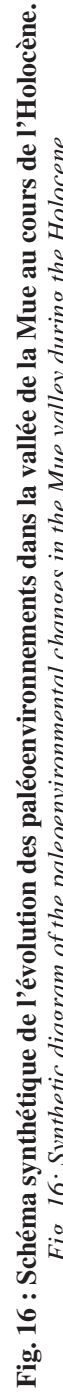


de l'activation de nombreuses sources en fond de vallon (Cairon) ou sur les versants de la vallée de la Mue (Thaon, Reviers) et d'une remontée concomitante des nappes phréatiques de fond de vallée qui explique le développement des zones humides à Cyperaceae (Reviers, Cairon) bordées de fougères (Reviers, Cairon), et de Composées Tubiliflores (Cairon) et d'un sol hydromorphe comme à Fontaine-Henry. La forêt est bien développée (chênes et noisetiers). Elle joue un rôle fondamental dans la stabilisation des versants et la faible turbidité des écoulements. Cette phase qui apparaît comme la signature sédimentaire de l'Optimum Climatique Holocène est proche de celle enregistrée dans les autres parties du Bassin de Paris (Pastre et al., 1997, 2002a, b, 2003a, b ; Orth, et al., 2004). Cette époque est marquée par la sédentarisation des populations locales au cours du Néolithique Ancien. Localement, les différents vestiges pouvant être attribués avec certitude à cette tranche chronologique concernent plutôt les plateaux dominant la vallée (Lepaumier et Chancerel, à paraître). Mais ces premières sociétés sédentaires n'ont pas laissé de marques déchiffrables dans les enregistrements sédimentaires de fond de vallée.

\section{4 - ATLANTIQUE RÉCENT $\left(6000-4700{ }^{14} \mathrm{C} \mathrm{BP}\right)$}

Aux alentours de 6000 BP, la sédimentation carbonatée prend moins de place dans le fond de vallée. La construction de l'édifice de tuf de Thaon se poursuit alors que les séquences tourbeuses se développent comme à Rots, à Cairon entre $6242+/-49{ }^{14} \mathrm{C} \mathrm{BP}$ et $5108+/-47{ }^{14} \mathrm{C} \mathrm{BP}$ où elles caractérisent l'ensemble de l'Atlantique Récent. La sédimentation devient également plus organique à Reviers entre $6000{ }^{14} \mathrm{C} \mathrm{BP}$ environ et $5315+/-60{ }^{14} \mathrm{C} \mathrm{BP}$. Les analyses polliniques développées dans les séquences tourbeuses montrent le développement au milieu de la période des zones humides à Cyperaceae (Rots, Reviers, Cairon) et localement à Phragmites (Cairon). Peut-être faut-il voir dans cette phase, marquée par la remontée des nappes phréatiques, le résultat d'une plus grande humidité témoignant d'une phase plus fraîche et plus humide attestée autour de 5500-5000 ${ }^{14} \mathrm{C}$ BP (Magny, 1995). À cette phase succède une période plus sèche (environ 5400$4700{ }^{14} \mathrm{C} \mathrm{BP}$ ) comme le suggèrent les malacofaunes de Thaon et le développement de l'aulnaie (Cairon, Reviers-R4S). Celle-ci est également enregistrée dans la vallée de la Seine et le nord de la France (Magny, 1995 ; Sebag, 2002). Plus généralement, les formations boisées (chênes, noisetiers) occupent toujours une place importante même si de nombreuses traces d'anthropisation des milieux (activités agro-pastorales, habitats, ensembles funéraires, mégalithes) sont détectées au cours du Néolithique Moyen sur l'ensemble de la vallée (Desloges, 1997 ; Ghesquière et Marcigny, sous presse). L'action des sociétés ne semble pas encore avoir d'impact notable sur le fonctionnement des systèmes morphosédimentaires.

\section{5 - DÉBUT DU SUBBORÉAL (4700-3500 ${ }^{14} \mathrm{C}$ BP)}

Le début du Subboréal marque un changement profond dans la sédimentation. On observe sa généralisation et son développement dans l'ensemble du fond de vallée. L'édifice tufacé de Reviers continue à se construire mais la sédimentation carbonatée cesse sur le tuf de Thaon. A l'amont (milieu du tronçon 2, tronçon 3a) une sédimentation carbonatée à passées tourbeuses se développe alors que vers l'aval, derrière les édifices tufacés de Thaon (tronçon $3 b$ ) et de Reviers (tronçon 4), la sédimentation organique s'impose à partir de $4500{ }^{14} \mathrm{C}$ BP environ. Elle vient recouvrir progressivement vers l'amont les formations carbonatées du début du tronçon 3 et du bouchon de tuf de Thaon vers 3500 ${ }^{14} \mathrm{C}$ BP. Partout, dans le fond de vallée, se développent des zones humides de grande extension avec un écoulement mal chenalisé comme en atteste la présence de zones humides à Cyperacées et des ceintures de fougères qui les accompagnent. Cela témoigne de la permanence d'un niveau élevé des nappes phréatiques. L'anthropisation semble du même ordre qu' au cours de la période précédente même si le développement de la sédimentation dans l'ensemble du fond de vallée ainsi que la faiblesse locale de l'aulnaie par rapport à la plupart des régions normandes à la même époque (Elhaï, 1963 ; Huault, 1972 ; Clet-Pellerin et al., 1977 ; CletPellerin et al., 1987 ; Sebag, 2002 ; Clet-Pellerin et Verron, 2004 ; Lespez et al., 2004) peut être interprété comme un reflet de l'action progressive des sociétés sur le milieu humide et du développement diffus d'une érosion des sols sur les versants. Ceci est en accord avec les données archéologiques qui montrent durant cette phase (Néolithique Final et première partie du Bronze Ancien), des traces d'occupation plus nombreuses sur les plateaux comme peut en témoigner l'éperon barré de Basly fouillé par G. San Juan (2003, 2004). Il n'existe pas dans le bassin versant de la Mue de preuves tangibles d'une intensification de l'activité fluviale vers $4000{ }^{14} \mathrm{C} \mathrm{BP}$ contrairement à ce qui est enregistré dans le bassin de Paris et dans de nombreuses régions européennes (Macklin, 1999 ; Pastre et al., 2002a, b ; Pastre et al., 2003a, b ; Orth et al., 2004).

\section{6 - LA FIN DU SUBBORÉAL (3500-2800 ${ }^{14} \mathrm{C}$ BP)}

Sur les tronçons 2, 3 et 4, la sédimentation organique est fréquemment ravinée par un horizon détritique limoneux qui comporte de nombreuses concrétions et fragments de concrétions carbonatées. Cette séquence témoigne de l'érosion des formations limoneuses et carbonatées et d'une plus grande capacité de transport de la Mue indiquant un retour à des écoulements mieux chenalisés. Des datations obtenues au sommet de la séquence tourbeuse sous-jacente sur le troisième (S3) et le quatrième tronçon (FHC) permettent de dater indirectement cette séquence. Elle se met en place respectivement après $3300+/-40{ }^{14} \mathrm{C} \mathrm{BP}$ et $3245+/-45{ }^{14} \mathrm{C}$ $\mathrm{BP}$. Elle peut être expliquée par une réactivation du système fluvial associée à la phase humide de Pluvis 
comme dans le centre du bassin de Paris (Pastre et al., 2003a, b) et en Angleterre (Macklin, 1999). Mais elle indique également une plus grande fourniture sédimentaire qui doit être rapprochée de l'apparition dans les diagrammes polliniques de la culture des céréales ( $\mathrm{FH}$, Reviers-R4S) et du développement des plantes rudérales et de prairies au cours de l'Âge du Bronze à l'image de ce qui a été mis en évidence plus au sud de la plaine de Caen (vallée du Laizon, Germain-Vallée et Lespez, sous presse) et dans le centre du Bassin parisien (Pastre et al., 2002a, b ; Pastre et al., 2003b). D'ailleurs, cette époque est marquée par une densification de l'occupation humaine (en particulier à l'âge du Bronze Moyen et au début du Bronze Final). Les plateaux sont occupés par des enclos (comme à Thaon ; Marcigny, 2001) et les versants de la vallée sont très probablement le siège des activités agro-pastorales. La fin de cet épisode n'a pas encore été précisément datée. Sur les tronçons 2 et 3 , il est souvent suivi d'un retour des milieux tourbeux de courte durée avant les transformations profondes du début du Subatlantique.

\section{7 - LE SUBATLANTIQUE (APRÈS $2800{ }^{14} \mathrm{C} \mathrm{BP}$ )}

Même si de rares secteurs conservent une sédimentation tourbeuse, la sédimentation limoneuse issue de l'érosion des limons loessiques déposés sur les plateaux vient progressivement colmater tout le fond de vallée au Subatlantique. A Fontaine-Henry (FH), la tourbe devient franchement limoneuse après $2420+/ 40$ ${ }^{14} \mathrm{C}$ BP et montre même de véritables passées de limons de débordement. Cette sédimentation traduit la multiplication des apports colluvio-alluviaux à partir des versants, comme cela a pu être mis en évidence à Fontaine-Henry, ou à l' amont du bouchon de tuf de Reviers (R4S, Clet-Pellerin et al., 1990), et leur redistribution par débordement au cours d'épisodes de crues très chargées en limons. Cette transformation complète des milieux sédimentaires qui se généralise au début du Subatlantique résulte d'une accentuation de l'anthropisation. Les données archéologiques montrent une complexification du modèle d'occupation à partir du Bronze Final et au premier Âge du Fer, époque durant laquelle de nombreux petits habitats et des nécropoles essaiment sur les plateaux (Rots, Cairon, Thaon). Puis au cours du deuxième Âge du Fer et du début de l'Antiquité, de grands établissements agricoles qui livrent un mobilier archéologique abondant et de nombreux carporestes (culture des céréales - blés, orges, avoines - et des légumineuses - pois, féveroles -) sont disséminés dans l'ensemble de la Plaine de Caen. Ils indiquent une véritable gestion de terroirs agricoles de plusieurs centaines d'hectares par des groupes de fermes (San Juan et al., 1999). Dans les diagrammes polliniques, à partir de l'Âge du Fer, la végétation arborée et arbustive (chênes, noisetiers) devient très faible (Rots, FontaineHenry) y compris dans les fonds de vallée et les marques des activités agricoles s'imposent avec un enregistrement des céréales et le développement des plantes rudérales et de prairie (Rots, $\mathrm{FH}$ ).
Les analyses palynologiques attestent également des fluctuations paléohydrologiques de la Mue. A Rots comme à Fontaine-Henry, la période $2700-2300{ }^{14} \mathrm{C} \mathrm{BP}$ se traduit par une augmentation nette des plantes de zones humides indiquant une remontée de la nappe phréatique sans doute en relation avec une pulsation plus fraîche et plus humide enregistrée en Europe de l'Ouest (Magny, 1995 ; Van Geel et al., 1996) et dont les répercussions semblent également se faire sur d'autres vallées normandes (Sebag, 2002 ; Germain-Vallée et Lespez, sous presse) et plus généralement du nordouest de l'Europe (Brown, 1997 ; Macklin, 1999 ; Pastre et al., 2002a, b; Pastre et al., 2003a). Cette conjonction de facteurs anthropiques et d'une oscillation hydro-climatique est sans doute responsable de la transformation des systèmes hydro-sédimentaires de la vallée de la Mue au début du Subatlantique. L'importance de l'occupation agricole du sol au cours des deux derniers millénaires dans la vallée de la Mue explique que cette évolution morphosédimentaire demeure même si ponctuellement des zones tourbeuses persistent dans le fond de vallée et que des remontées de la nappe phréatique sont encore enregistrées comme entre 1500-1000 ${ }^{14} \mathrm{C}$ BP (Rots, FH). L'impact d'éventuelles périodes de déprise agricole et du Petit Age Glaciaire sur les paysages et les systèmes morpho-sédimentaires n'a pas été enregistré contrairement à d'autres régions normandes (Clet-Pellerin et Verron, 2004 ; Lespez et al., 2004) ou du nord de la France (Pastre et al., 2003a, b, sous-presse). Il est vrai que ce dernier est intervenu dans un contexte où les flux hydriques étaient particulièrement bien maîtrisés du fait de la mise en place d'un système bief-moulin généralisé sur l'ensemble du bassin versant (Lespez et al., 2005).

\section{CONCLUSION : LA COMPLEXITÉ DES SYSTÈMES MORPHOSÉDIMENTAIRES HOLOCÈNES}

Les recherches entreprises appuyées sur des observations géomorphologiques et biostratigraphiques nouvelles permettent la mise en place d'une première chronostratigraphie pour les remplissages des fonds de vallées de la Plaine de Caen. Elles soulignent l'appartenance de la vallée de la Mue aux systèmes hydrosédimentaires holocènes $\mathrm{du}$ bassin de Paris. Les fluctuations climatiques semblent l'élément dynamique expliquant les transformations des systèmes hydrosédimentaires de la vallée de la Mue du Boréal jusqu'à la fin du Subboréal malgré une occupation humaine ancienne (dès le Mésolithique) bien attestée dans le bassin versant. Les conséquences des actions humaines sur les milieux sédimentaires de fond de la vallée n'apparaissent que tardivement à partir de l'Âge du Bronze puis de l'Âge du Fer mais elles imposent alors durablement leur marque.

Ces travaux soulignent la forte homogénéité du remplissage de fond de vallée pendant la première comme la dernière partie de l'Holocène (jusqu'au Boréal et à 
partir de la charnière Subboréal-Subatlantique) et sa variabilité longitudinale à partir de $8500{ }^{14} \mathrm{C} \mathrm{BP}$ et jusque vers $3500{ }^{14} \mathrm{C} \mathrm{BP}$. Tout au long de l'Atlantique et du Subboréal, coexistent trois types de dynamiques sédimentaires holocènes : une sédimentation tufacée, une sédimentation organique et une sédimentation mixte.

La construction d'édifices tufacés de grande ampleur est diachronique, la première partie de l'Holocène pour Thaon, les deux derniers tiers pour Reviers et le début du Subboréal pour l'amont de la vallée (tronçon 2 et 3 ). La sédimentation carbonatée apparaît d'abord étroitement dépendante des conditions locales et en particulier de la circulation des eaux dans les calcaires du Bathonien. Dans le contexte tectonique du nord de la Plaine de Caen, la localisation des exsurgences est peut-être à mettre en relation avec des failles drainantes. En revanche, à partir de $2500{ }^{14} \mathrm{C} \mathrm{BP}$, le rôle des sociétés devient prépondérant. Pour le dernier millénaire, le rôle de l'artificialisation de l'écoulement et de la gestion des sources joue un rôle majeur dans l'absence de dépôts carbonatés significatifs. Mais le tarissement de la sédimentation tufacée est progressif et antérieur. Il s'amorce à partir de $3500{ }^{14} \mathrm{C} \mathrm{BP}$ et se généralise à partir de $2500{ }^{14} \mathrm{C} \mathrm{BP}$ alors que la sédimentation limoneuse s'impose, témoignant du développement de l'érosion hydrique et des écoulements turbides. Ces observations confirment localement le rôle des sociétés dans le déclin de la sédimentation tufacée autour de $2500{ }^{14} \mathrm{C}$ BP (Goudie et al., 1993) pour une région sédimentaire où les cultures céréalières occupent une place prépondérante depuis longtemps (Verron, 2000).

Localement mise en place dès la première partie de l'Holocène, la sédimentation tourbeuse est prépondérante dans le remplissage holocène de la vallée de la Mue à partir du Subboréal (4500 ${ }^{14} \mathrm{C}$ BP environ). Le rôle de la construction progressive des édifices tufacés dans le déclenchement et le développement et l'expansion des remplissages tourbeux apparaît important comme le suggéraient Clet-Pellerin et al. (1990). Les concrétions mobiles accumulées à Thaon et à Reviers forment progressivement de vastes édifices qui deviennent de véritables obstacles à l'écoulement favorisant vraisemblablement le maintien durable de zones humides en arrière. Ainsi, dans un contexte de niveau élevé des nappes phréatiques, la sédimentation tourbeuse apparaît pendant un temps au moins comme une forme d'ajustement du système fluvial à la perturbation engendrée par les obstacles carbonatés.

Malgré son aspect partiel, cette première recherche montre la complexité spatio-temporelle des systèmes hydro-sédimentaires holocènes d'une petite vallée de la Plaine de Caen. Elle souligne ainsi la nécessité de prendre en compte les discontinuités longitudinales qui résultent d'héritages géomorphologiques et tectoniques anté-holocènes complexes et de phénomènes d'auto-régulation des systèmes morphosédimentaires y compris pour des cours de faible ordre et dans des contextes qui paraissent a priori très homogènes. De nouvelles recherches géomorphologiques et paléoenvironnementales menées en collaboration avec les archéologuues seront nécessaires pour affiner localement la connaissance des variations latérales du remplissage holocène et plus généralement la résolution chronologique et spatiale des connaissances sur l'évolution des fonds de vallées de la Plaine de Caen et au-delà en Basse-Normandie (Lespez et al., 2004 ; Marcigny et al., soumis).

\section{REMERCIEMENTS}

Cette recherche a pu bénéficier du soutien du Service Régional de l'Archéologique de Basse-Normandie et du Service Départemental de l'Archéologie du Calvados sous la forme d'une prospection thématique d'une durée de trois ans. Elle s'est également appuyée sur le soutien d'une ACI «Jeunes chercheurs » du Fonds National pour la Science intitulée «Gestion de l'eau et dynamiques des paysages du Néolithique à nos jours : étude des basses vallées côtières dans le nord-ouest de la France » (resp. L. Lespez). Nous tenons plus particulièrement à remercier Guy San Juan, Cyril Marcigny et Jean-Michel Cador pour leur aide tout au long de ce travail ainsi que Sylvie Coutard et Laurent Deschodt pour leurs critiques constructives et leurs suggestions.

\section{BIBLIOGRAPHIE}

ADOLPHE \& ROFES, 1973 - Les concrétionnements calcaires de la Levrière (affluent de l'Epte, sous-affluent de la Seine, Département de l'Eure. Bulletin de l'Association française pour l'Étude du Quaternaire, 2, 79-87.

ANTOINE P., FAGNARD J.-P., LIMONDIN-LOZOUET N., PONEL P. \& MUNAUT A.-V., 2000 - Le Tardiglaciaire du Bassin de la Somme : élément de synthèse et nouvelles données. Quaternaire 11, 85-98.

ANTOINE P., MUNAUT A. V., LIMONDIN-LOZOUET N., PONEL P. \& DUPERON J.-M., 2003 - Modification of fluvial system in relation to climatic modifications during the Lateglacial and early Holocene in the Somme Basin (Northern France). Quaternary Science Reviews 22, 2061-2076.

BROWN A. G., 1997 - Alluvial geoarchaeology, Floodplain archaeology and environmental change. Cambridge manuals in Archaeology, Cambridge University Press, Cambridge, 377 p.

CADOR J.-M., CANTAT O. \& LESPEZ L., 2001 - Un tableau de bord pour les SAGE, Proposition d'outil de gestion et d'évaluation pour les Schémas d'Aménagement et de Gestion des Eaux sur le bassin versant de la Mue (Calvados), Actes du colloque "Hydrosystème, Paysage, territoire", Commission "Hydrosystèmes continentaux" du Comité National Français de Géographie, 6-8 septembre 2001, Lille, 7 p, CD-Rom.

CLEMENT-SAULEAU S., GHESQUIERE E., LE GOFF I. \& MARCIGNY C., 2000 - Habitats et monuments du Néolithique moyen : le dolmen de Cairon «La pierre tourneresse » (Calvados). Communication préliminaire, Internéo 3, Journée d'Information du 2/12/2000, 85-101

CLET-PELLERIN M., 1997 - Sondages palynologiques du château de Rots. Rapport non publié, Service Régional de l'Archéologie de Basse Normandie, $13 \mathrm{p}$.

CLET-PELLERIN M., HUAULT M.F., LARSONNEUR C. \& PELLERIN J., 1977 - La Basse Vallée de l'Orne. Le remblaiement périglaciaire et postglaciaire. L'évolution paléogéographique et l'histoire de la végétation. Bulletin Société Linnéenne de Normandie, Caen, 105, 23-44.

CLET-PELLERIN M., HELLUIN M., PELLERIN J. \& PAREYN C., 1990 - Le Tuf de Reviers (Calvados). Actes du Colloque "Tufs et travertins quaternaires des bassins de la Seine et de la Somme, et des Régions limitrophes" (Rouen, 1989). In Bulletin du Centre de Géomorphologie de Caen, 38, 199-213. 
CLET-PELLERIN M. \& VERRON G., 2004 - Influence de l'Homme sur l'évolution des paysages normands pendant l'Holocène. In Richard H. (dir.), Néolithisation précoce. Premières traces d'anthropisation du couvert végétal à partir de données polliniques. Annales Littéraires 77, Série Environnement, sociétés et archéologies, 7, Presses Universitaires Franc-Comtoises, Besançon, 53-68.

COUTARD J.-P., HELLUIN M., OZOUF J.-C. \& PELLERIN J., 1973 - Carte des Formations Superficielles et Carte géomorphologique de Bayeux-Courseulles au 1/50 000. Bulletin du Centre de Géomorphologie de Caen, 17.

DELAHAYE F. \& NIEL C., 2004 - Thaon, Eglise Saint-Pierre. Bilan Scientifique de la région Basse-Normandie 2003. DRAC Basse-Normandie, Service Régional de l'Archéologie de Basse Normandie, 19-20.

DELIBRIAS G., 1985 - Le carbone 14. Méthodes de datation par les phénomènes nucléaires naturels : application. Eds. Roth E., Poty B., Coll. CEA, Masson (Paris), 421-458

DESLOGES J., 1997 - Les premières architectures funéraires de Basse-Normandie, Actes du colloque international "La culture de Cerny, nouvelle économie, nouvelle société au Néolithique" (Nemours, 1994) in Mémoires du Musée de Préhistoire d'Ile-deFrance, 6, 515-539.

ELHAÏ H., 1963. - La Normandie occidentale entre la Seine et le golfe normano-breton. Etude morphologique. Thèse de doctorat, Bordeaux, Bière, $581 \mathrm{p}$.

EVANS J.G., 1972 - Land snails in Archaeology. Seminar Press, London \& New York, $436 \mathrm{p}$

FOLK R.L. \& WARD W.C., 1957 - Brazos River bar, a study in the significance of grain size parameters. Journal of Sedimentary Petrology, 27, 514

FONT M., 2002 - Signature géomorphologique des déformations en domaine intraplaque : application à la Normandie. Doctorat. Université de Caen, 421 p.

FREYTET P., 1990 - Contribution à l'étude des tufs du bassin de $\mathrm{Pa}$ ris. Actes du Colloque "Tufs et travertins quaternaires des bassins de la Seine et de la Somme, et des Régions limitrophes" (Rouen, 1989), Bulletin du Centre de Géomorphologie de Caen, $\mathbf{3 8}$, 9-47.

GERMAIN-VALLEE C. \& LESPEZ, sous presse - Dynamique holocène d'un fond de vallée normand (Laizon, Calvados), approche géomorphologique et micromorphologique. In (Allée P. et Lespez L. (eds). Actes de la Table Ronde en l'honneur de René NeboitGuilhot. Collection "Nature et Société", Presses Universitaires Blaise Pascal, Clermont Ferrand, 4 p.

GHESQUIERE E. \& MARCIGNY C. (dir.), sous presse - $L a$ "Pierre Tourneresse » à Cairon (Calvados). Un habitat puis un monument funéraire du Néolithique moyen, $101 \mathrm{p}$.

GOUDIE A.S., VILES H.A. \& PENTECOST A., 1999 - The Late Holocene tufa decline in Europe, The Holocene 3, 2, 181-186.

HUAULT M.F., 1972 - Recherches sporo-polliniques sur le Postglaciaire des vallées de l'Orne et de la Dives. Bulletin Société Linnéenne de Normandie, Caen, 46-57.

KERNEY M.P., CAMERON R.A.D. \& JUNGBLUTH J.H., 1983 Die Landschnecken Nord- und Mitteleuropas. Paul Parey, Hamburg und Berlin, $384 \mathrm{p}$.

LAUTRIDOU J.P., 1985 - Le cycle périglaciaire pléistocène en Europe du Nord-Ouest et plus particulièrement en Normandie. Thèse d'Etat, Caen. Centre de Géomorphologie du CNRS, éd., 908 p.

LEPAUMIER H. \& CHANCEREL A., à paraître - Les bracelets en pierre découverts en Basse-Normandie, Bulletin de la Société des Antiquaires de Normandie, à paraître au premier semestre 2005.

LESPEZ L., CLET-PELLERIN M., DAVIDSON R. \& MARCIGNY C., avec la collaboration de Levalet F. et Hardel B., 2004 - Evolution des paysages et anthropisation depuis le Néolithique dans la péninsule de La Hague. Revue d'Archéométrie 28, $71-88$

LESPEZ L., GARNIER E., CADOR J.-M. \& ROCARD D., 2005 Les aménagements hydrauliques et la dynamique des paysages des petits cours d'eau depuis le XVIII ${ }^{\mathrm{e}}$ siècle dans le nord-ouest de la France, l'exemple du bassin versant de la Seulles (Calvados). In La rivière aménagée. Entre héritages et modernité. Formes, techniques et mise en æuvre. Aesturia, 7, 89-109+ 3 pl. couleur.
LESUEUR P., LESOURD S., LEFEBVRE D., GARNAUD S. \& BRUN-COTTAN J.-C., 2003 - Holocene and modern sediments in the Seine Estuary (France): a synthesis. Journal of Quaternary Science 18 (3-4), 339-349.

LIMONDIN-LOZOUET N., 2002 - Impact des oscillations climatiques du Tardiglaciaire sur l'évolution des malacofaunes de fond de vallée en Europe du Nord-Ouest. In H. Richard, A. Vignot (eds) Equilibres et ruptures dans les écosystèmes depuis 20000 ans en Europe de l'Ouest. Presses Universitaires Franc-Comtoises, Besançon, 45-51.

LIMONDIN-LOZOUET N. \& ANTOINE P., 2001 - Palaeoenvironmental changes inferred from malacofaunas in the Lateglacial and Early Holocene fluvial sequence at Conty (Northern France). Boreas, 30, 148-164.

LIMONDIN-LOZOUET N. \& PREECE R.C., 2004 - Molluscan successions from the Holocene tufa of St Germain-le-Vasson, Normandy (France) and their biogeographical significance. Journal of Quaternary Science, 19 (1), 55-71.

LIMONDIN-LOZOUET N., GAUTHIER A. \& PREECE R.C., 2005 - Enregistrement des biocénoses de la première moitié de l'Holocène en contexte tufacé à Saint Germain-le-Vasson (Calvados). Quaternaire, ce volume.

MACKLIN M.G., 1999 - Holocene river environments in Prehistoric Britain: human interaction and impact. Quaternary Proceedings, 7, 521-530.

MAGNY M., 1995 - Palaeohydrological changes in Jura (France), and climatic oscillations. Géographie Physique et Quaternaire. 49, 3, 401-408.

MARCIGNY C., 2001 - L'Age du Bronze en Basse-Normandie, volumes 1 et 2, mémoire D.E.A., sous la direction de J. Guilaine, Université de Toulouse-le-Mirail / EHESS, 2001, 82 p. et 122 fig.

MARCIGNY C., LESPEZ L., GHESQUIERE E. \& CLETPELLERIN M., soumis - Emprise ou déprise agricole à l'Âge du Bronze moyen sur le littoral de la Manche ? Une lecture du phénomène gràce aux sites normands. Actes du Congrès CTHS de Besançon (avril 2004), 12 p.

MAURIZOT P., AUFFRET J.-P., BAIZE S., DEROIN J.-P., DUGUE O., FILY G., LE GALL J., LELIEPAULT F., MAZENC B. \& PELLERIN J., 2000 - Carte géologique de France : Bayeux-Courseulles. BRGM

ORTH P., PASTRE J.-F, GAUTHIER A., LIMONDINLOZOUET N. \& KUNESH S., 2004 - Les enregistrements morphosédimentaires et biostratigraphiques des fonds de vallée du bassin versant de la Beuvronne (Bassin parisien, Seine et Marne, France): perception des changements climato-anthropiques à l'Holocène. Quaternaire 15 (3), 285-298.

PASTRE J.-F, FONTUGNE M., KUZUCUOGLU C., LEROYER C., LIMONDIN-LOZOUET N. \& TALON M., 1997 - L'évolution Tardi- et Postglaciaire des lits fluviaux au nord-est de Paris (France). Relation avec les données paléoenvironnementales et l'impact anthropique sur les versants. Géomorphologie 4, 291 312 .

PASTRE J.-F, LEROYER C., LIMONDIN-LOZOUET N., FONTUGNE M., HATTE C. \& KRIER V., 2002a - L'Holocène du Bassin parisien : variations environnementales et réponses géoécologiques des fonds de vallées. In Richard H. et Vignot A. (Eds), Equilibres et ruptures dans les écosystèmes depuis 20000 ans en Europe de l'Ouest. Annales Littéraire de 1'Université de FrancheComté, Série Environnement, Sociétés et Archéologie 3, Besançon, 39-45.

PASTRE J.-F, LEROYER C., LIMONDIN-LOZOUET N., ORTH P., CHAUSSE C., FONTUGNE M., GAUTHIER A., KUNESH S., LE JEUNE Y. \& SAAD M.-C., 2002b - Variations paléoenvironnementales et paléohydrologiques durant les 15000 derniers millénaires : les réponses morphosédimentaires des vallées du Bassin parisien. In Bravard J.-P. et Magny M. (Dir.) - Les fleuves ont une histoire, paléo-environnement des rivières et des lacs français depuis 15000 ans, Errance, Paris, 29-44.

PASTRE J.-F., LEROYER C., LIMONDIN-LOZOUET N., ANTOINE P., GAUTHIER A., LE JEUNE Y. \& ORTH P., 2003a - Quinze mille ans d'environnement dans le Bassin parisien (France) : mémoires sédimentaires des fonds de vallée. In Des milieux et des hommes : fragments d'histoires croisés, Elsevier, Paris, 43-55 
PASTRE J.-F., LIMONDIN-LOZOUET N., LEROYER C. \& PONEL P., 2003b - River System evolution and environmental changes during the Late Glacial in the Paris Basin (France). Quaternary Science Reviews 22, 2177-2188.

PASTRE J.-F., A., ORTH P., LE JEUNE Y. \& BENSAADOUNE sous presse - L'homme et l'érosion dans le Bassin parisien (France). La réponse morphosédimentaire des fonds de vallée au cours de la seconde partie de l'Holocène. In Allée, P. et Lespez L. (eds.), Actes de la Table Ronde en l'honneur de René Neboit-Guilhot. Collection "Nature et Société", Presses Universitaires Blaise Pascal, Clermont Ferrand, $8 \mathrm{p}$.

PONEL P, MATTERNE V. \& COULTHARD N., 2000 - La Tène and Gallo-roman natural environments and Human impact at the Touffréville Rural Settlement, reconstructed from Coleoptera and Plant macroremains (Calvados, France). Journal of Archaeological Science, 27, 1055-1072.

PUISSEGUR J.J., 1976 - Mollusques continentaux quaternaires de Bourgogne. Mémoires Géologiques de l'Université de Dijon 3, Doin, Paris, $241 \mathrm{p}$

SAN JUAN G., MENIEL P., MATTERNE-ZECK V., SAVARY X. \& JARDEL K., 1999 - L'occupation gauloise au Nord-Ouest de Caen. L'évaluation en sondage du plateau de Thaon (Calvados). Revue Archéologique de l'Ouest, 16, p. 131-194.
SAN JUAN G., 2003 - Basly-La Campagne. Bilan Scientifique de la région Basse-Normandie 2001. DRAC Basse-Normandie, Service Régional de l'Archéologie de Basse Normandie, 17.

SAN JUAN G., 2004 - Basly-La Campagne. Bilan Scientifique de la région Basse-Normandie 2003. DRAC Basse-Normandie, Service Régional de l'Archéologie de Basse Normandie, 19-20.

SEBAG D., 2002 - Apports de la matière organique pour la reconstitution des paléoenvironnements holocènes de la basse vallée la Seine, fluctuations des conditions hydrologiques locales et environnements de dépôt. Doctorat, Université de Rouen, $356 \mathrm{p}$.

STUIVER M. \& POLLACH H., 1977 - Discussion reporting of ${ }^{14} \mathrm{C}$ data. Radiocarbon, 19, 355-363.

STUIVER M. \& REIMER P., 1993 - Extended 14C data base and revised Calib. 3.0 14C age calibration programme. Radiocarbon, 35, 215-230.

VAN GEEL B., BUURMAN J. \& WATERBOLK H.T., 1996 - Arachaeological and palaeocological indications about an abrupt climate change in The Netherlands, and evidence for climatological teleconnections around $2650 \mathrm{BP}$, Journal of Quaternary Science, 9: $109-118$.

VERRON G., 2000 - Préhistoire de la Normandie. Ouest-France Université, Rennes, 364 p. 